\title{
Microfabrication of a Segmented-Involute-Foil Regenerator, Testing in a Sunpower Stirling Convertor, and Supporting Modeling and Analysis
}

\author{
Mounir B. Ibrahim ${ }^{1}$ \\ Cleveland State University, Cleveland, Ohio, 44115 \\ Roy C. Tew ${ }^{2}$ \\ NASA Glenn Research Center, Cleveland, Ohio, 44135 \\ David Gedeon ${ }^{3}$ \\ Gedeon Associates, Athens, Ohio, 45701 \\ Gary Wood ${ }^{4}$ \\ Sunpower, Inc., Athens, Ohio, 45701 \\ and \\ Jeff McLean ${ }^{5}$ \\ Mezzo Technologies, Baton Rouge, LA 70806
}

Under Phase II of a NASA Research Award contract, a prototype nickel segmented-involute-foil regenerator was microfabricated via LiGA and tested in the NASA/Sunpower oscillating-flow test rig. The resulting figureof-merit was about twice that of the $\sim \mathbf{9 0 \%}$ porosity random-fiber material currently used in the $\mathbf{s m a l l} \mathbf{5 0 - 1 0 0} \mathrm{W}$ Stirling engines recently manufactured for NASA. That work was reported at the 2007 International Energy Conversion Engineering Conference in St. Louis, was also published as a NASA report, NASA/TM-2007-214973', and has been more completely described in a recent NASA Contractor Report, NASA/CR-2007-215006 ${ }^{2}$. Under a scaled-back version of the original Phase III plan, a new nickel segmentedinvolute-foil regenerator was microfabricated and has been tested in a Sunpower Frequency-Test-Bed (FTB) Stirling convertor. Testing in the FTB convertor produced about the same efficiency as testing with the original random-fiber regenerator. But the high thermal conductivity of the prototype nickel regenerator was responsible for a significant performance degradation. An efficiency improvement (by a 1.04 factor, according to computer predictions) could have been achieved if the regenerator been made from a low-conductivity material. Also the FTB convertor was not reoptimized to take full advantage of the microfabricated regenerator's low flow resistance; thus the efficiency would likely have been even higher had the FTB been completely reoptimized. This report discusses the regenerator microfabrication process, testing of the regenerator in the Stirling FTB convertor, and the supporting analysis. Results of the pre-test computational fluid dynamics (CFD) modeling of the effects of the regenerator-test-configuration diffusers (located at each end of the regenerator) is included. The report also includes recommendations for accomplishing further development of involute-foil regenerators from a higher-temperature material than nickel.

\section{Nomenclature}

$\mathrm{A}=$ wetted area, in hydraulic diameter definition

$\mathrm{D}_{\mathrm{h}}=$ hydraulic diameter

$f \quad=$ Oscillating frequency, Hz, or Darcy friction factor
$\mathrm{Nu} \quad=\quad$ Nusselt number

${ }^{1}$ Professor, Mechanical Engineering Department, 1960 E. $24^{\text {th }}$ St., Rm. 261, Stillwell Hall, AIAA Associate Fellow.

${ }^{2}$ Research Engineer, Thermal Energy Conversion Branch, 21000 Brookpark Rd., MS 301-2, AIAA Member

${ }^{3}$ President, Gedeon Associates, 16922 South Canaan Road

${ }^{4}$ Chief Engine Designer, Sunpower Inc., 182 Mill Street

${ }^{5}$ Director of Engineering, International Mezzo Technologies, 7167 Florida Blvd.

American Institute of Aeronautics and Astronautics 092407 


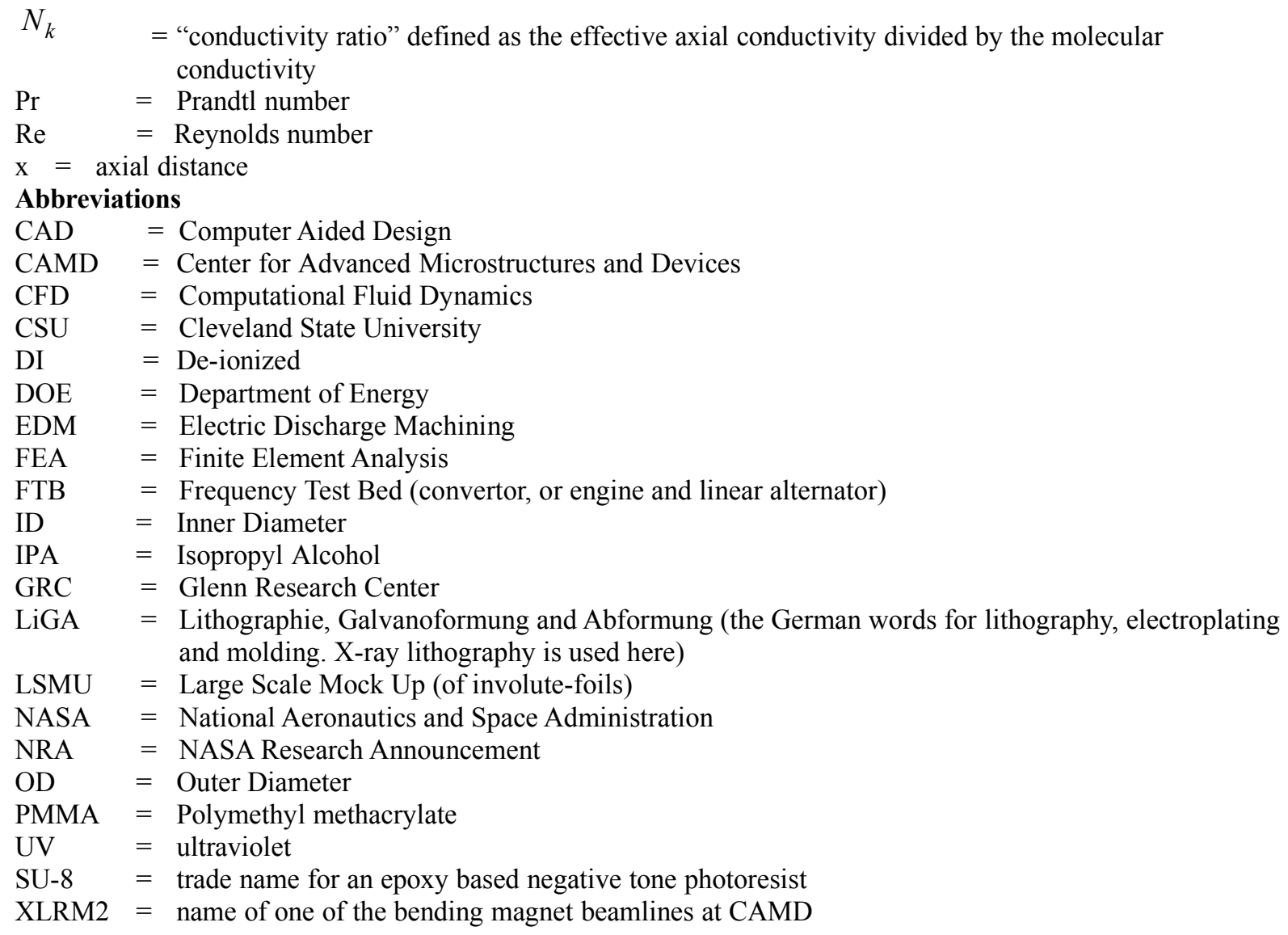

\section{Introduction}

$\mathrm{T}$ HE Stirling-engine regenerator has been called "the crucial component," Organ ${ }^{3}$, in the Stirling-cycle engine. The regenerator, which obtains heat from the hot working fluid and releases heat to the cold working fluid, recycles the energy internally, allowing the Stirling cycle to achieve high efficiency. The location of the regenerator within a Stirling convertor is shown in Figure 1.

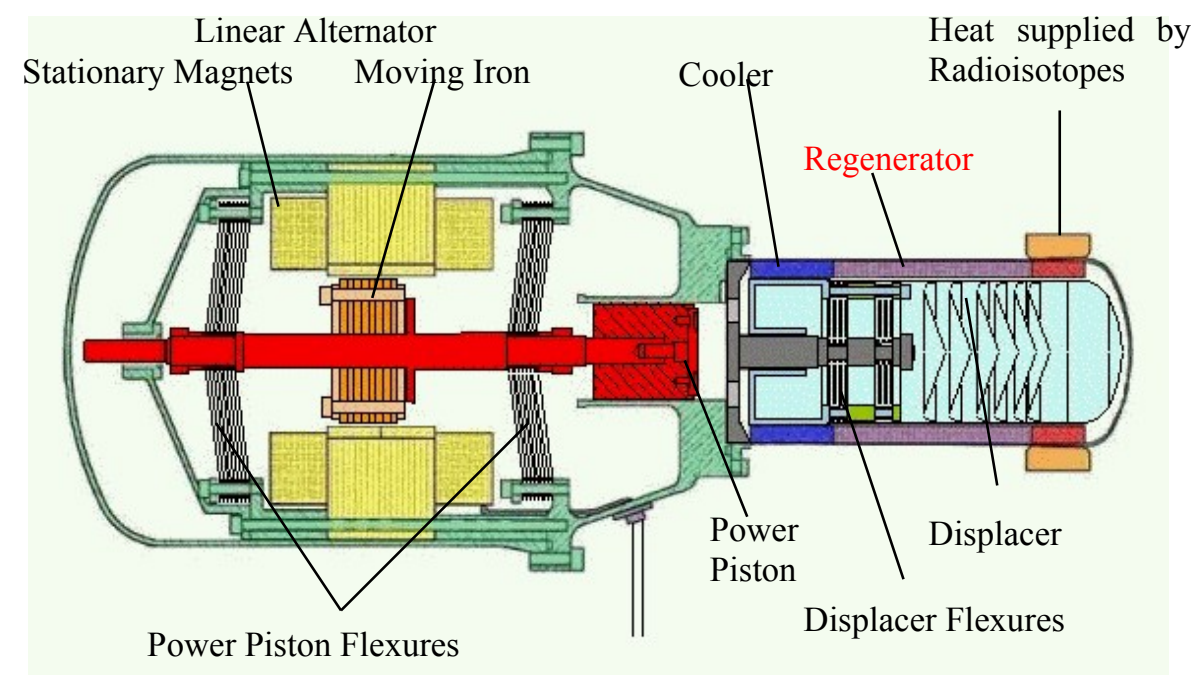

Figure 1. Schematic of Stirling convertor showing the location of the regenerator. 
Currently, regenerators are usually made of woven screens or random fibers. Woven-screen regenerators have relatively high flow friction. They also require long assembly times which tends to increase their cost. Random fiber regenerators also have high flow friction but are easy to fabricate and therefore are inexpensive. Figure 2 shows a typical random-fiber regenerator and Figure 3 shows a close up of the fibers. Due to the method of fabrication, the fibers are random primarily in a plane perpendicular to the main flow path. Thus both woven screens and random fibers experience flow primarily across the wires (cylinders in cross flow). Cylinders in cross flow tend to cause flow separation resulting in high flow friction and considerable thermal dispersion, a thermal loss mechanism that causes an increase in apparent axial thermal conduction. For space engines, there must be assurance that no fibers of this matrix will eventually work loose and damage vital convertor parts during the mission. It is also important that local variations in porosity inherent to random fiber regenerators will result in local mismatches in flow channels which would contribute to axial thermal transport. Wire screens have some randomness associated with their stacking and thus may have locally non-uniform flow. The efforts thus far have shown that attractive features for effecting high fluid-to-matrix heat transfer with low pressure drop are a matrix in which: a) the heat transfer surface is smooth, b) the flow acceleration rates are controlled, c) flow separation is minimized and d) passages are provided to allow radial mass flow for a more uniform distribution when the inlet flow or the in-channel characteristics are not radially uniform. It is thought that properly designed microfabricated regular geometries could not only reduce pressure drop, maintain high heat transfer and allow some flow redistribution when needed, but could show improved regenerator durability for long missions.

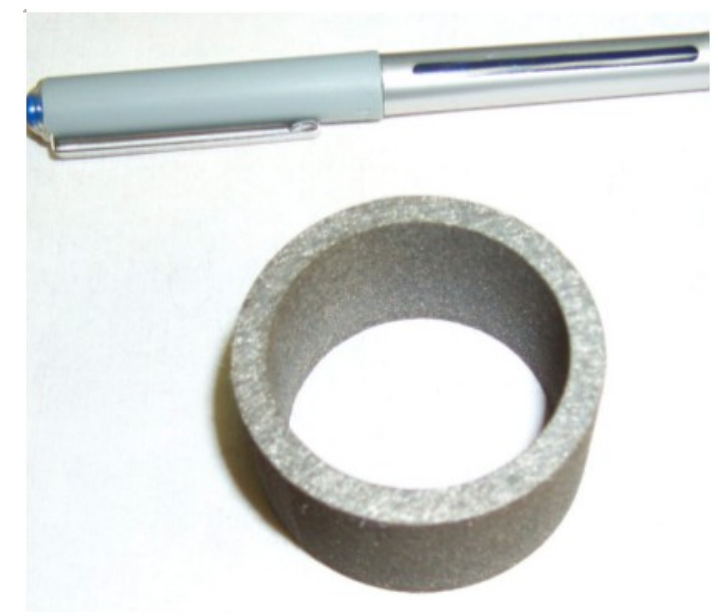

Figure 2. Random Fiber

Regenerator.
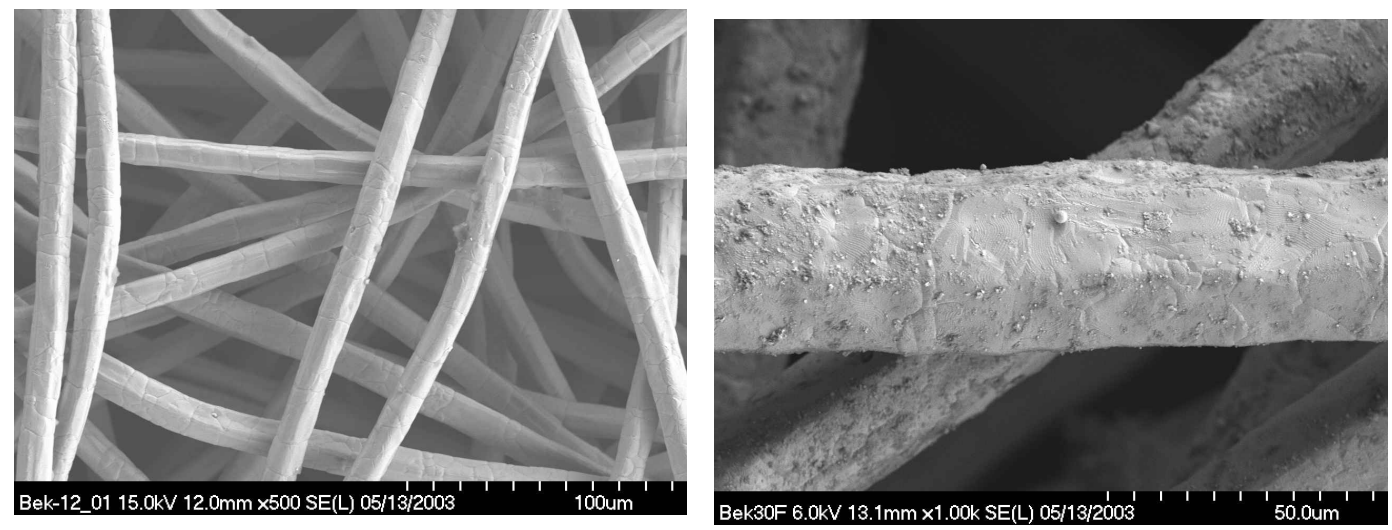

Figure 3. Electron micrography of a random fiber regenerator matrix. Courtesy of NASA Glenn Research Center. 
The goal of the current NASA project was to develop a new regenerator of high durability as well as high efficiency using emerging microfabrication technology. In addition to the benefit to Stirling convertor space-power technology, such regenerator development will also benefit Stirling cycle coolers and NASA's many cryocoolerenabled missions. This project was conducted in three phases, I, II and III.

In Phase I of this project, a microscale regenerator design was developed based on state-of-the-art analytic and computational tools. For this design, a 6-9\% engine-efficiency improvement was projected. A manufacturing process was identified and a vendor (International Mezzo Technologies) was selected to apply it. Mezzo completed EDM tools for fabricating layers of the chosen involute-foil microregenerator design, based on the team's specifications. They were ready to begin producing regenerator layers (annular portions of disks) by the end of Phase I. Also, a Large-Scale-Mock-Up (LSMU) involute-foil regenerator was designed and fabrication had begun. Computational Fluid Dynamics (CFD) analysis for different geometries was employed to model the fluid flow and heat transfer under both steady and oscillatory-flow conditions. The effects of surface roughness were included ${ }^{4}$. Several geometries: lenticular ${ }^{5}$, parallel plates (equally/non-equally spaced), staggered parallel plates (equally/nonequally spaced) and 3-D involute-foils were studied via CFD. The modeling was applied to both the microscale involute-foil regenerator and to the LSMU model of it.

The Phase II report ${ }^{2}$ of this project covered in detail the preliminary design process that was used for adapting a micro-fabricated regenerator to a Sunpower FTB (Frequency-Test-Bed) Stirling convertor ${ }^{6}$. The FTB convertors produce about $80-90 \mathrm{~W}$ of electrical power with a heat input of $220 \mathrm{~W}$ and are the direct ancestors of the advanced Stirling convertors now under development by Sunpower and GRC for future NASA space missions. They were originally designed for random-fiber regenerators. During phase II, several tasks were completed: a) Developed a preliminary micro-fabricated regenerator design based on its similarity to a parallel-plate structure, b) Analyzed radiation losses down the void part of the regenerator, c) Analyzed thermal conduction losses in the solid part of the regenerator, using closed form as well as two-dimensional computational analysis, d) Built a prototype microfabricated regenerator for use in the NASA/Sunpower oscillatory flow test rig, e) Tested that regenerator and derived design correlations for heat transfer and pressure drop, and f) Performed system modeling of a FTB engine with a microfabricated regenerator using the Sage simulation software ${ }^{7}$ - first using a theoretical parallel-plate correlation for heat transfer and pressure drop, then with the correlations derived from actual test data.

During phase III we finalized the regenerator design, built and installed it in a FTB Stirling convertor, tested it, and analyzed the test results. The rest of this paper covers the activities performed under Phase III.

\section{Regenerator Final Design (Summarized by Gedeon Associates)}

\section{Detailed Specifications}

According to the Sage computer simulation, Table 1 shows the regenerator design that produces the best efficiency under the constraints of the FTB installation.

\section{Table 1. FTB Regenerator Dimensions.}

\begin{tabular}{|l|l|}
\hline \multicolumn{2}{|c|}{ FTB Regenerator Dimensions } \\
\hline Channel gap (mm) & $0.086(+.001,-.001)$ \\
\hline Web wall thickness $(\mathrm{mm})$ & $0.014(+.001,-.001)$ \\
\hline Inner \& Outer wall thickness $(\mathrm{mm})$ & $0.030(+.005,-.005)$ \\
\hline
\end{tabular}

The involute geometry is composed of primary and alternate disks, designed to be alternated in the stackup assembly. A CAD drawings of the two disks is shown in Figures 4a and b. 

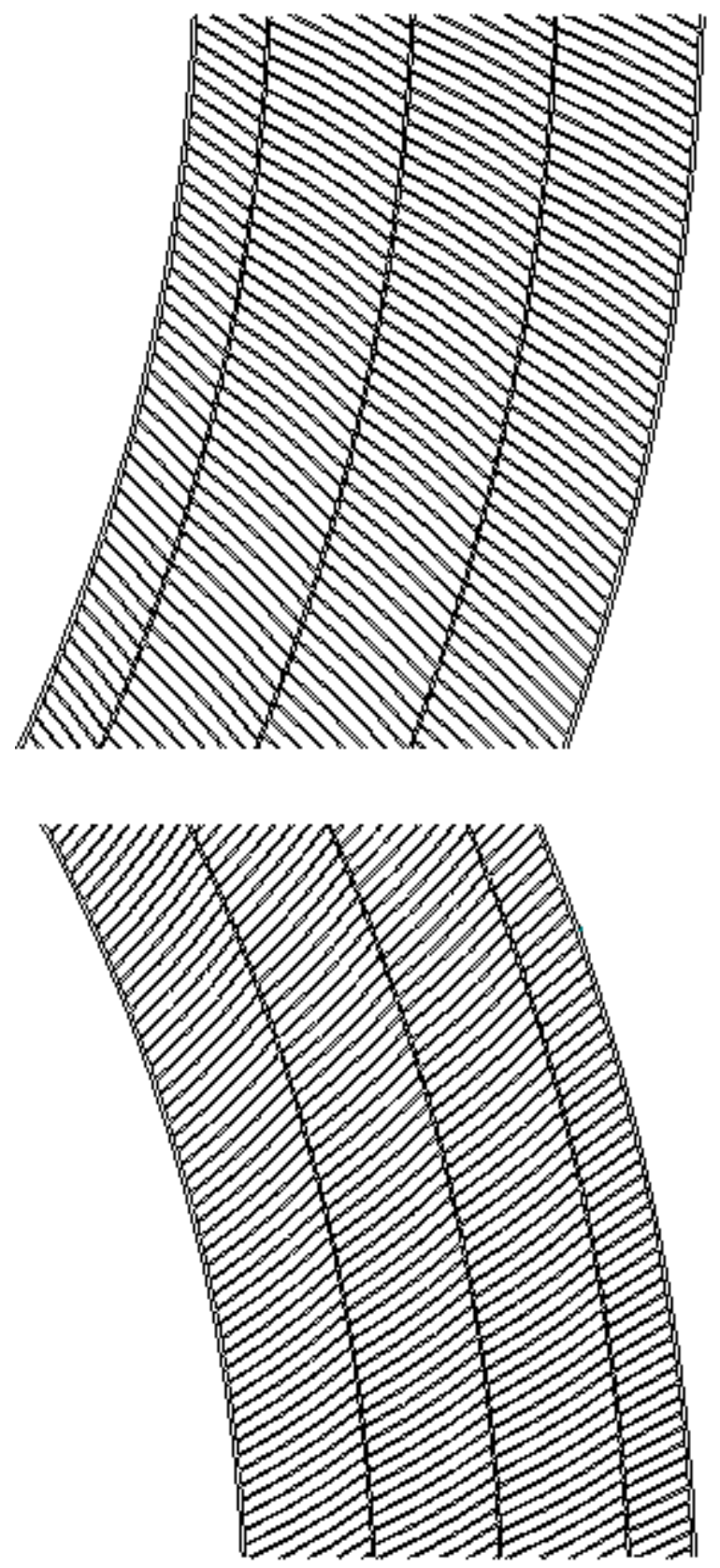

Figure 4a. A CAD drawing of the involute

disk, primary.
Figure 4b. A CAD drawing of the involute

disk, alternate. 
Hydraulic diameter and porosity for the above disks are $D_{\mathrm{h}}=0.159 \mathrm{~mm}$ and $\beta=0.837$ respectively, which are close to the optimized values as determined with the Sage model.

These drawings do not show any rounded corners where foil elements meet partition circles. We decided to round the corners in the production disks to facilitate the manufacturing process and because rounded corners had produced good results in the phase II prototype regenerator. There was some concern over non-uniform flow patterns in sharp corners and also structural weakening due to stress concentrations there.

\section{Jet Diffuser Design}

Random fiber flow diffusers are located at either end of the regenerator for purposes of spreading the incoming flow jets from the narrow channels of the acceptor or rejector heat exchangers. The diffuser concept is sketched below (see Figure 5) with the arrows attempting to convey the idea of the gas flow field upstream and downstream of the diffuser. The diffuser design was backed by 2-D computational modeling at Cleveland State University, as will be shown later, in section III.

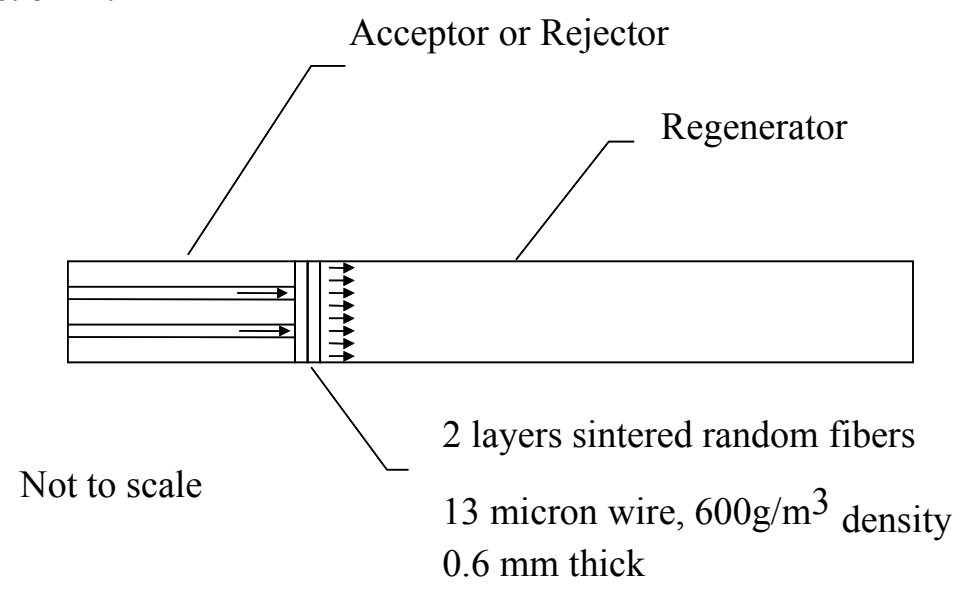

Figure 5. A Sketch of the Jet Diffuser Model.

The $600 \mathrm{~g} / \mathrm{m}^{3}$ material density for the random fiber material refers to the density of a material previously supplied by Bekaert Corp. which was readily available for use. That material compressed to $0.6 \mathrm{~mm}$ thickness results in a porosity of $\beta=0.88$.

In addition to diffusing jets, the diffusers also accommodated irregularities in the FTB regenerator cavity (region between displacer cylinder OD and pressure-wall ID) at the two ends. At the rejector end, part of the piston cylinder extends into the regenerator space by $0.8 \mathrm{~mm}$, resulting in a tapered regenerator cavity there. At the acceptor end there may have been a small braze fillet where the acceptor heat exchanger joins to the pressure wall.

The diffuser disks have a nominal thickness of $0.6 \mathrm{~mm}$ but we intended to adjust thickness as necessary by compressing the random fiber material more or less. The nominal regenerator stack-up height would be achieved by stacking an integral number of precisely made $0.500 \mathrm{~mm}$ thick regenerator disks. Our original intention was to use two diffuser disks at the rejector end of the regenerator (to clear the piston cylinder intrusion) and one at the acceptor end. As a result of quality control issues during the polishing process, it turned out the regenerator disks were not precisely $0.5 \mathrm{~mm}$ thick (see below, section V) nor was the assembly process as smooth as we had hoped. The clearance between the regenerator disk ID and displacer hot cylinder was too tight and the disks did not slide onto the cylinder smoothly. We stacked the disks onto the displacer cylinder starting from the rejector end. When we got to the acceptor end, we found it necessary to leave out the last regenerator disk and use two diffuser disks in order to best fill the remaining gap between the regenerator face and cavity end. As a result we have one extra regenerator disk that was not installed in the engine (total number of disks installed was 126).

\section{Thermal Expansion and Assembly Issues}

The length of the space occupied by the regenerator is defined by the outer pressure wall of the heater head. A calculation shows that the relative thermal expansion between the nickel regenerator and stainless-steel pressure wall is only about $0.030 \mathrm{~mm}$ in heating from room temperature to operating temperature, with the pressure wall expanding more. The thermal expansion calculations were based on the values given in Table 2 below. 
Table 2. Thermal Expansion Coefficient for Nickel and SS.

\begin{tabular}{|l|l|}
\hline Material & Coef. Thermal expansion (ppm per C) \\
\hline High purity Nickel (70-1000F) & 15.5 \\
\hline 304 stainless steel (32-212 F) & 17.3 \\
\hline
\end{tabular}

After installation there was easily this amount of resilience in the regenerator assembly to accommodate the anticipated expansion. The regenerator disk stack itself was not rigid as one might expect had all the disks been precisely $0.500 \mathrm{~mm}$ thick with flat faces. Instead the local variations in disk thickness resulted in a large number of small random gaps between disks, so that the regenerator could be compressed elastically on the order of $0.1 \mathrm{~mm}$ or more, depending on applied pressure. There is also some resiliency in the random-fiber material. Room temperature experiments at Sunpower showed sintered random fiber samples rebound elastically by about $2 \%$ after removal of the applied force. For $2 \mathrm{~mm}$ total thickness of random fiber material, this suggests an elastic rebound of $0.040 \mathrm{~mm}$, which would in itself accommodate the required $0.030 \mathrm{~mm}$ due to thermal expansion.

\section{Jet Boundary Conditions}

Table 3 below shows the jet boundary conditions as obtained from Sage ${ }^{7}$.

Table 3. Jet Boundary Conditions.

\begin{tabular}{|l|l|}
\hline \multicolumn{2}{|c|}{ Rejector } \\
\hline Pressure $(\mathrm{Pa})$, mean, amplitude and phase angle & $3.10 \mathrm{E} 6+4.1 \mathrm{E} 50,-22 \mathrm{deg}$ \\
\hline Mass flow rate $(\mathrm{kg} / \mathrm{s})$, amplitude and phase angle & $4.6 \mathrm{E}-3 @ 44 \mathrm{deg}$ \\
\hline Mean temperature $(\mathrm{C})$ & 43 \\
\hline Mean density $\rho_{m}\left(\mathrm{~kg} / \mathrm{m}^{3}\right)$ & 4.8 \\
\hline Velocity amplitude $u_{1}(\mathrm{~m} / \mathrm{s})$ & 9.6 \\
\hline Pressure head amplitude $\rho_{m} u_{1}^{2} / 2(\mathrm{~Pa})$ & $2.2 \mathrm{E} 2$ \\
\hline Mean jet spacing $\left(A_{\text {regen }} / N_{\text {jets }}\right)^{0.5}(\mathrm{~mm})$ & 1.8 \\
\hline \multicolumn{2}{|c|}{ Acceptor } \\
\hline Pressure $(\mathrm{Pa})$, mean, amplitude and phase angle & $3.10 \mathrm{E} 6+4.0 \mathrm{E} 5 @-24 \mathrm{deg}$ \\
\hline Mass flow rate $(\mathrm{kg} / \mathrm{s})$, amplitude and phase angle & $1.8 \mathrm{E}-3 @-12 \mathrm{deg}$ \\
\hline Mean temperature $(\mathrm{C})$ & 624 \\
\hline Mean density $\rho_{m}\left(\mathrm{~kg} / \mathrm{m}^{3}\right)$ & 1.7 \\
\hline Velocity amplitude $u_{1}(\mathrm{~m} / \mathrm{s})$ & 17 \\
\hline Pressure head amplitude $\rho_{m} u_{1}^{2} / 2(\mathrm{~Pa})$ & $2.5 \mathrm{E} 2$ \\
\hline Mean jet spacing $\left(A_{\text {regen }} / N_{\text {jets }}\right)^{0.5}(\mathrm{~mm})$ & 1.3 \\
\hline \multicolumn{2}{|c|}{ Rejector jet diffuser layer } \\
\hline Pressure drop amplitude $(\mathrm{Pa})$ & $1.2 \mathrm{E} 3$ \\
\hline \multicolumn{2}{|c|}{ Acceptor jet diffuser layer } \\
\hline Pressure drop amplitude $(\mathrm{Pa})$ & $1.8 \mathrm{E} 3$ \\
\hline \multicolumn{2}{|c|}{ Microfab Regenerator } \\
\hline Pressure drop amplitude $(\mathrm{Pa})$ & $16.3 \mathrm{E} 3$ \\
\hline
\end{tabular}

\section{CFD Analysis (Cleveland State University)}

\section{A. CFD Geometry}

A 2-D geometry with parallel plates was chosen to simulate the jet diffuser model shown earlier in Figure 5. Simulating the actual geometry would require a 3-D geometry and thus more CPU and memory allocation. Figure 6 shows the 2-D geometry used to model the jet flow (from the FTB Acceptor) into a random fiber matrix (porous media) separating the acceptor and the involute-foil regenerator. The dimensions were selected based on data provided by Gedeon Associates to match the FTB design (see Figure 5 and Table 3). With $1.3 \mathrm{~mm}$ mean jet spacing (from Table 3), 650 microns (see Figure 6) equals $1 / 2$ of the mean jet spacing. Also, the distance from the jet exit to 
the involute-foil inlet (600 microns shown in Figure 6) corresponds to the $0.6 \mathrm{~mm}$ porous-material thickness. The 0.9 porosity approximates the porosity of 0.88 provided in Section II B. It should be noted that the jet enters from the west side with a half-width of 133 microns and the upper and lower boundaries of the CFD domain were chosen to be symmetric (as shown in the figure). With the dimensions given, six parallel plates were placed at $0.6 \mathrm{~mm}$ from the jet exit with metal thicknesses of 14 micron and 86 micron gaps.

$133 \mu \mathrm{m}$

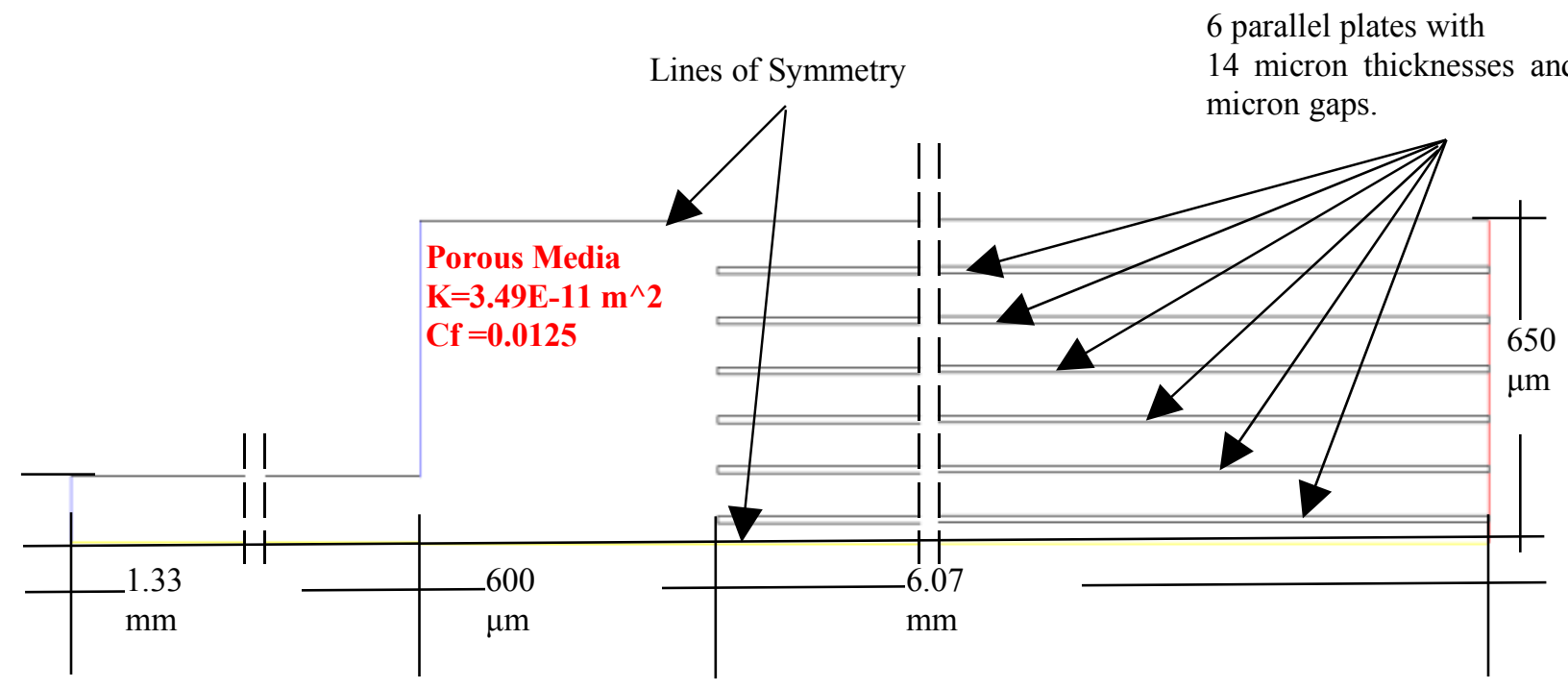

Figure 6. Geometry used to model the porous media (placed in the 600 micron thickness) between the acceptor outlet (shown as slot with 133 micron half thickness) and the involute-foil entrance (shown with 6 parallel plates, 14 micron metal thickness and 86 micron gap). The flow is from west to east and top and bottom planes are lines of symmetry.

\section{B. CFD Results}

The Fluent ${ }^{8}$ commercial code was utilized to simulate the above case in order to help validate the choice of diffuser dimensions. Version 6.3.26 was used with 213,560 cells. The code ran on a Dell Precision PWS670, Intel (R) Xeon (TM) with a $2.8 \mathrm{GHz}$ CPU. A steady flow with a V2f turbulence model was utilized in the simulation, and the input data shown in Table 4 were assumed.

Table 4. Input Data for CFD Simulation of Jetting through Porous-Media Diffuser into Simulated Involute-Foil Regenerator.

\begin{tabular}{|l|l|}
\hline Fluid & Air \\
\hline Pressure, $\mathrm{Pa}$ & 101,325 \\
\hline Temperature, $\mathrm{K}$ & 300 \\
\hline Jet Velocity, $\mathrm{m} / \mathrm{s}$ & 35.41 \\
\hline Permeability, $\mathrm{m}^{\wedge} 2$ & $3.49 \mathrm{E}-11$ \\
\hline Inertial Coefficient & 0.0125 \\
\hline Porosity & 0.9 \\
\hline
\end{tabular}

Figure 7, 8 \& 9 show CFD velocity vectors (colored by their magnitude) obtained for three different cases (of various gap/porous-media configurations between the jet exit and the involute-foil inlet): 1) without porous media (see Figure 7), 2) with porous media and a 133 micron axial gap between the jet exit and the porous media (see Figure 8), and 3) with porous media and no gap (see Figure 9). A big recirculation area is noticed in the case without any porous media, as expected. The case with the porous media and gap shows how the flow spreads out vertically before entering the porous media. The case with no gap (and with porous media) shows no recirculation at all as the flow passes through the porous media.

Figure 10 shows the pressure distribution along the flow direction starting from the jet exit. There is a pressure recovery (in the space between the jet exit and the involute-foil inlet) in the case without porous material (about 156 
$\mathrm{Pa}$ ). The pressure drop is $1595 \mathrm{~Pa}$ for the case with a gap upstream of the porous material and $2099 \mathrm{~Pa}$ for the case of no gap upstream of the porous material.

Figure 11 shows the mass flow rate in each channel of the involute-foil (normalized by the maximum flow rate, which occurs in Channel (1) - see Figure 7 for channel identification), for the three cases studied above. The best flow uniformity (which relates directly to reducing the regenerator losses) was obtained for the case with porous media and with a gap. These results combined with the results for the pressure drop shown in Figure 10 indicate the optimum case (of the three cases examined) is the one with a 133 micron gap and porous media. This case provides the lowest pressure drop and the best velocity uniformity entering the involute-foil.

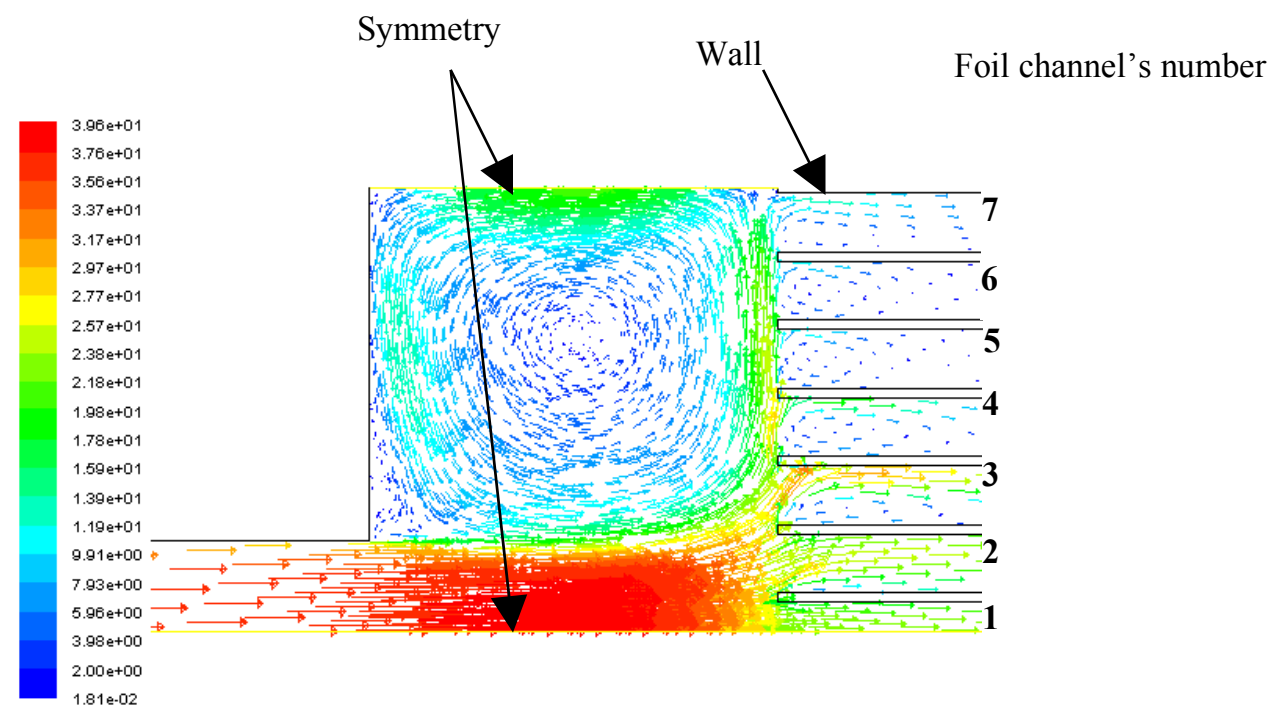

Figure 7. Velocity vectors colored by their magnitude, without porous media between the jet exit and involute foil inlet.

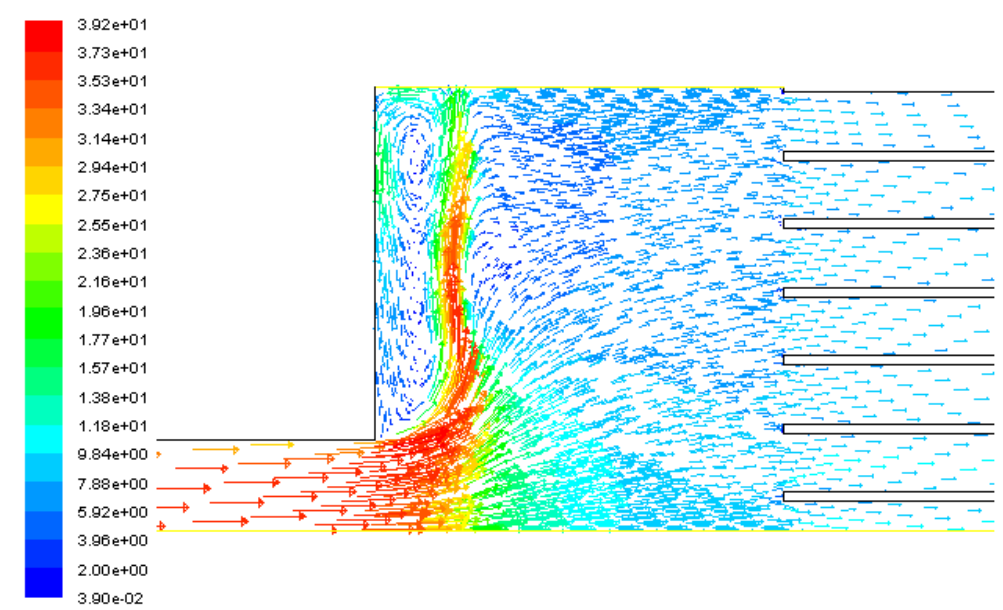

Figure 8 . Velocity vectors colored by their magnitude, with porous media and with a gap (133 micron) between the jet exit and the porous media. 


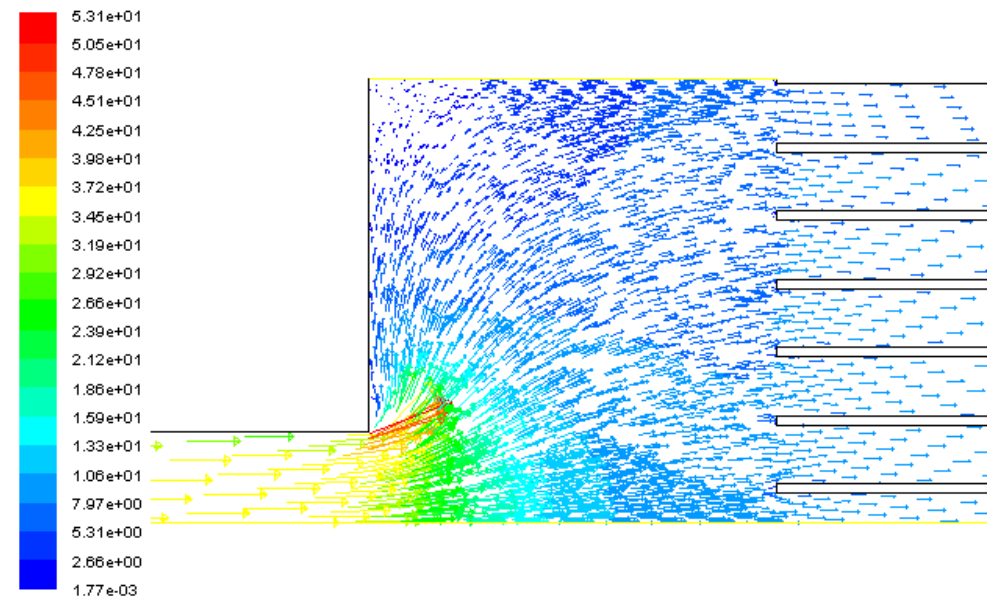

Figure 9. Velocity vectors colored by their magnitude, with porous media between the jet exit and involute foil inlet and without a gap.

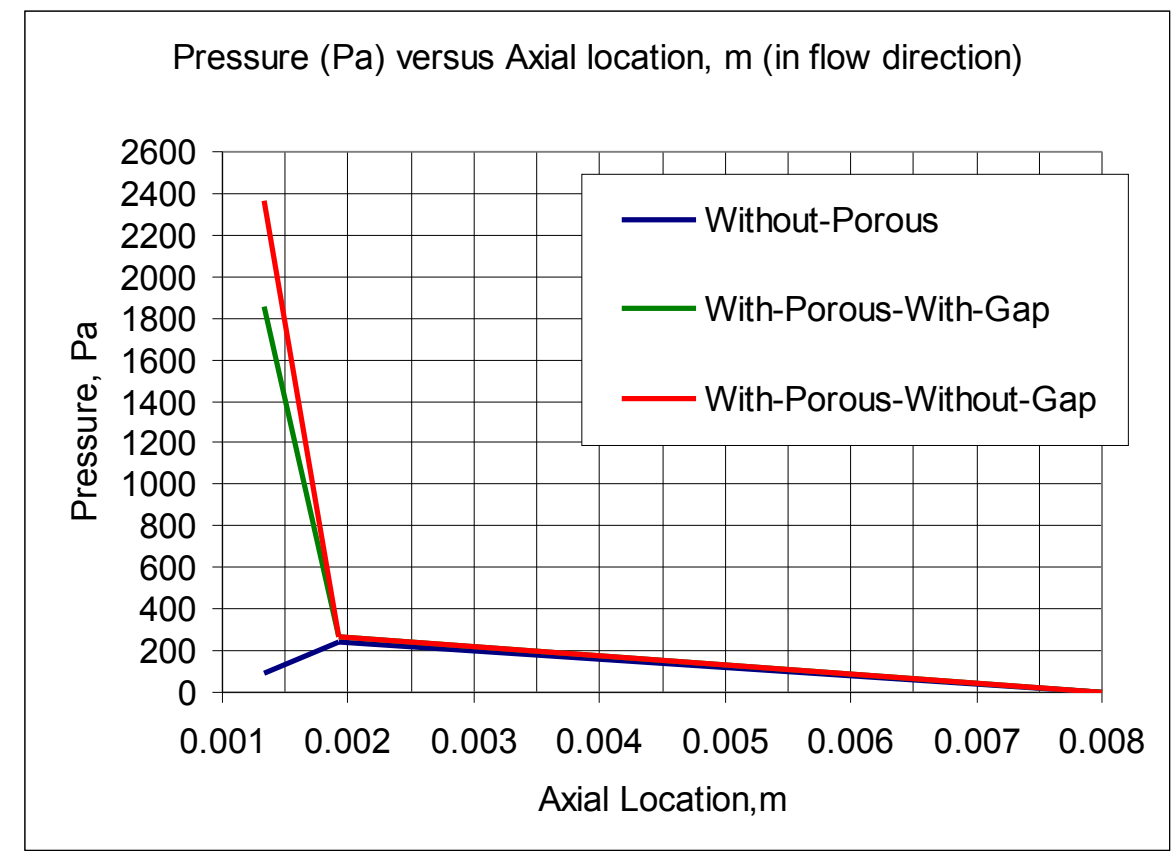

Figure 10. Pressure distribution along the flow direction starting from the jet exit.

There is a pressure recovery of about $156 \mathrm{~Pa}$ in the case without any porous media between the jet exit and involute foil inlet. The pressure drop in the cases with porous media are $1595 \mathrm{~Pa}$ with a gap between the jet exit and the porous media and $2099 \mathrm{~Pa}$ without a gap. 


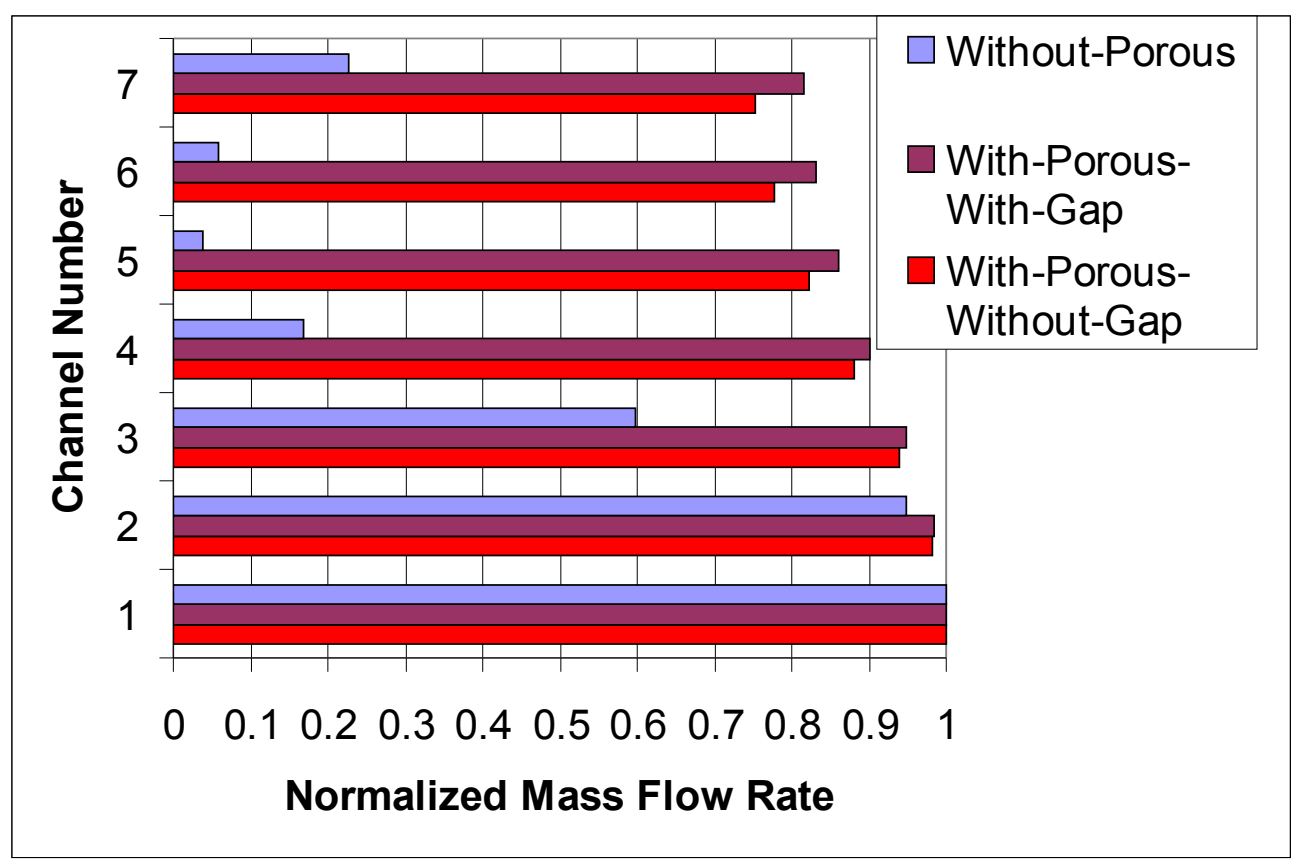

Figure 11. The mass flow rate in each channel normalized by the maximum flow rate, which occurs in channel (1), for the three cases studied?

\section{Regenerator Fabrication (International Mezzo Technologies)}

This section focuses on the contributions of Mezzo Technologies. In the previous phase of this program, Mezzo Technologies delivered a regenerator designed for benchmark testing on the NASA/Sunpower oscillatory-flow test rig. The original plan was to make this regenerator using a combination of the LiGA process and electrical discharge machining (EDM). However, the EDM process proved to be very slow, tool wear rate was high, and it became apparent that the probability of fabricating the desired regenerator using LiGA-EDM with the available funding was low. In order to deliver the initial regenerator on schedule, Mezzo changed its manufacturing approach from LiGAEDM to a standard LiGA process. The standard LiGA process was used to directly produce individual nickel regenerator components which were then assembled, sent to Cleveland State, and subsequently tested at Sunpower. The regenerator disks suffered from three key defects: under-plating, defects in the regenerator ribs, and contamination of the flow passages from wire EDM.

The goal of Phase III of this project was to build a regenerator for testing in an actual Stirling engine, which was free of the defects seen on the FTB regenerator. The under-plating problems, which were caused by high energy xray scattering, were eliminated by changing the substrate material from stainless steel to glass. With this simple material change, the $\mathrm{x}$-rays were able to pass directly through the substrate. The defects in the ribs were corrected by carefully fabricating the x-ray mask with very tight process control. Finally, the contamination problems arising from the use of wire EDM for planarization was corrected by changing to a polishing process.

By changing its fabrication strategy, Mezzo was able to provide the regenerator for the project and Sunpower was able to experimentally determine the regenerator performance. During the fabrication process, Mezzo developed several advanced processes for fabrication of the second regenerator. This paper provides a summary of the manufacturing process.

\section{A. LiGA-fabricated Regenerators}

\subsection{LiGA Process Overview}

The LIGA process consists of three steps: X-ray lithography, electroforming, and molding. The process is illustrated in Figure 12 and is described as follows:

A sheet of radiation-sensitive resist, bonded to a conductive metal substrate is placed behind an x-ray mask (see Figure 12). A collimated source of x-rays (emitted from an electron storage ring) is used to define features in the resist. The radiation passes through regions on the mask transparent to the impinging radiation (those areas not 
covered with an x-ray absorber) and is absorbed by the radiation-sensitive resist. Depending upon the tone of the resist (positive or negative), the resist is either made soluble (positive) or insoluble (negative) in a developer. In either case, following the exposure step, the resist is immersed in a developer, and the soluble resist is dissolved, resulting in well-defined polymer features. Then, an electroplating step is used to fill in the lithographically defined cavities in the resist. Following the electroplating step, the remaining resist is removed, leaving a field of electroplated metal micro features. LIGA is a preferred micro machining method to fabricate high aspect ratio micro features (features with extreme height/width ratios) with nearly vertical, smooth sidewalls. The Center for Advanced Microstructures and Devices (CAMD) in Baton Rouge, LA has a synchrotron storage ring that emits a synchrotron radiation spectrum ideal for x-ray lithography, or micro machining. This facility was used for the x-ray exposures of this project.

\subsection{Manufacturing Process for Stirling Regenerator}

In an effort to eliminate the cause of the undercutting, the 400-series stainless-steel substrates of the earlier Phase II involute foils were replaced. The new substrates were made of $\mathrm{SiO}_{2}$ glass disks that were 4.7-inches in diameter and completely free of any cracks or surface defects. The following steps give a synopsis of the fabrication process:

1) Each disk was soaked in trichloroethylene for 1 hour at room temperature. Then the disks were soaked in acetone, isopropyl alcohol (IPA) and finally in de-ionized (DI) water. Once this cleaning process was complete, the disks were dried with compressed air. They were then etched in a solution of sulfuric acid, hydrogen peroxide and DI water. The disks were finally flushed with DI water before being put into a convection oven to dry. This entire cleaning process ensured that the surface of each substrate was completely clean of any residue, especially any organic materials, and thoroughly dehydrated.

2) The clean substrates were delivered to CAMD for deposition of 2 microns of titanium on one face of each substrate. This titanium layer created an electrically conductive seed layer that could later be plated with nickel. The titanium-coated substrate was then returned to Mezzo for further processing. It was necessary to oxidize the titanium layer in order to reduce back scatter during x-ray exposure and to help form a mechanical bond with the PMMA wafer. This was done by soaking the titanium-coated substrate in a solution of hydrogen peroxide, sodium hydroxide and DI water. After oxidation, the substrates were flushed in DI water and then placed in a convection oven to dry (See Figure 13). 


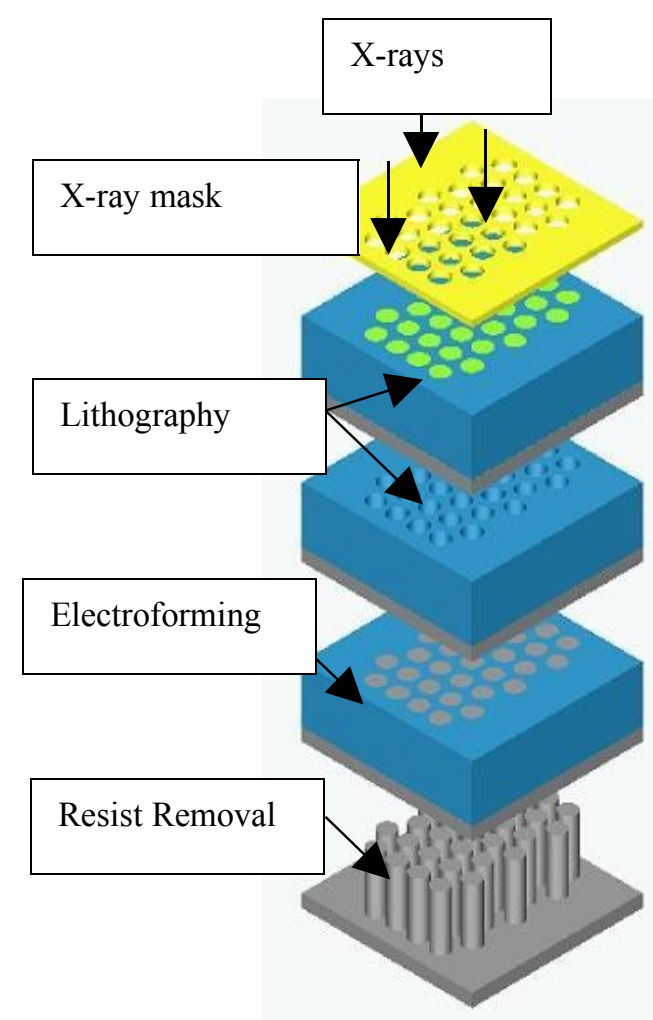

Figure 12. LiGA process overview.

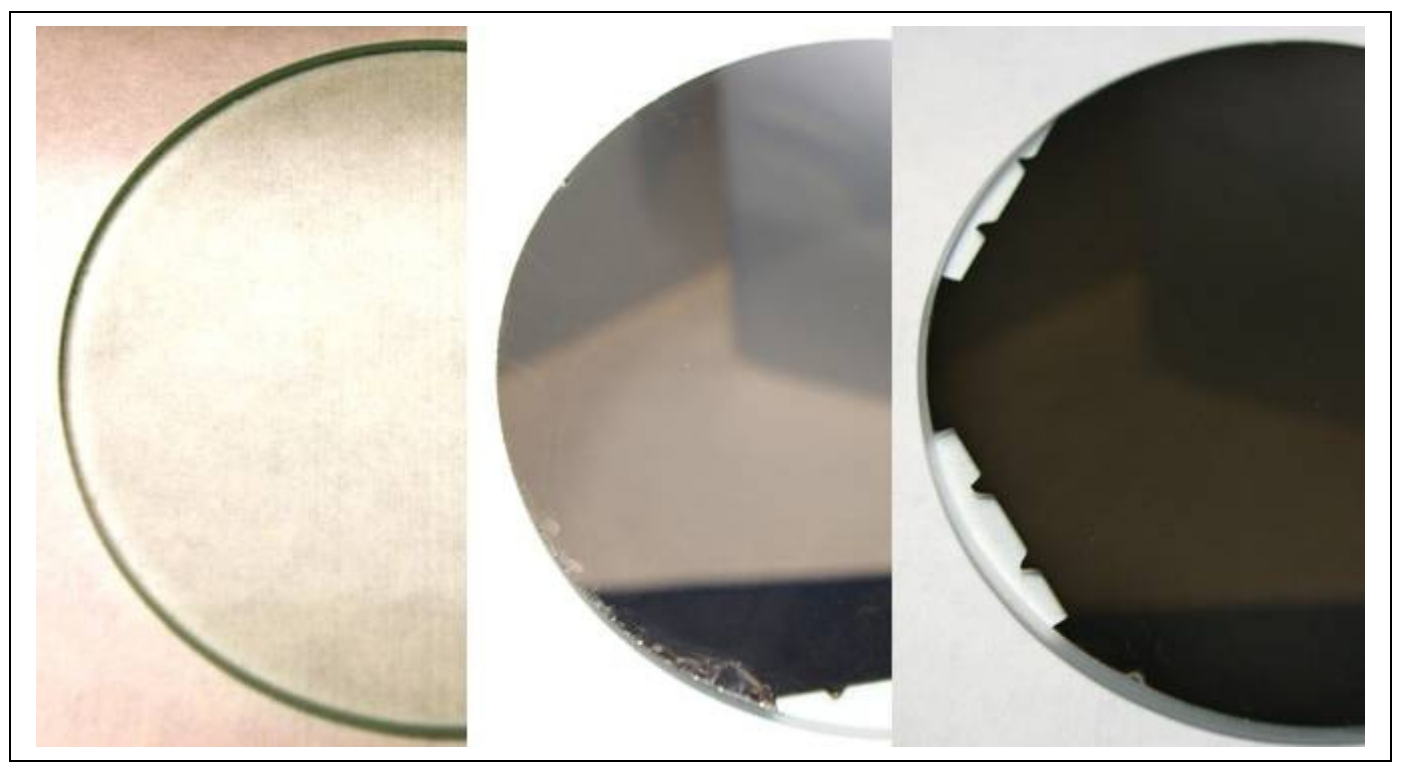

Figure 13. Fabrication progression from left to right:

clean glass substrate, titanium coated substrate, oxidized titanium layer.

3) When the substrates were thoroughly dried, a thin layer of liquid PMMA was applied to the titanium oxide layer. The liquid PMMA layer was baked until cured and a 2.5-mm PMMA wafer was then carefully bonded to each substrate. After the PMMA was bonded and allowed to thoroughly cure, the PMMA was fly- 
cut to the desired height of $500 \mathrm{~mm}$. This final step yielded a finished substrate ready for exposure (See Figure 14).

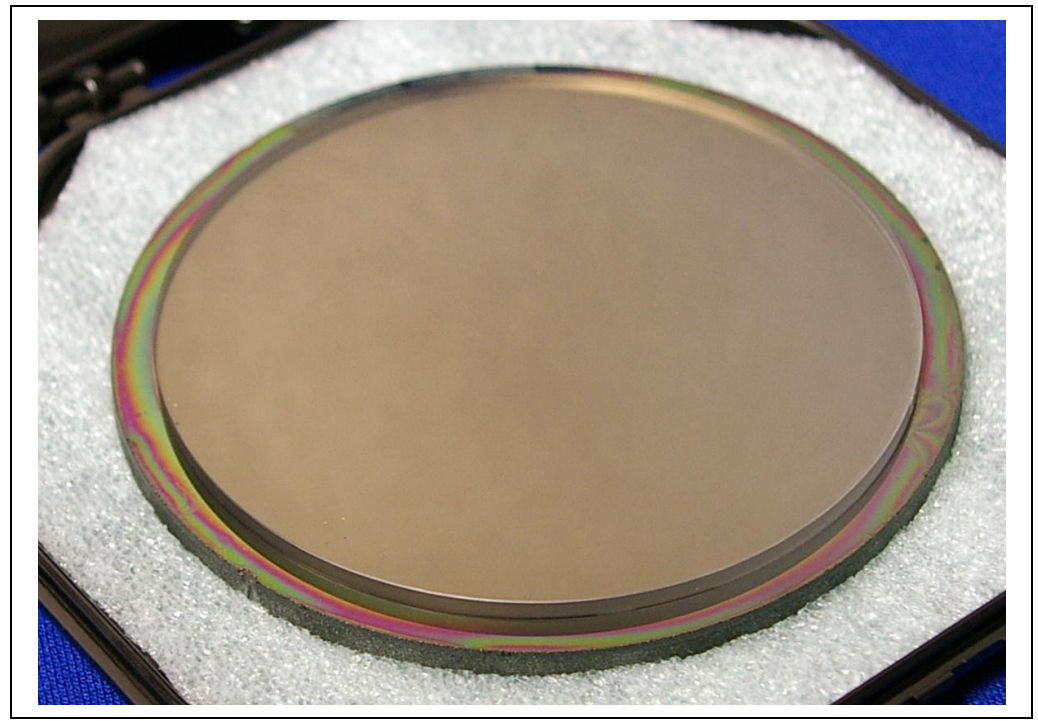

Figure 14. PMMA wafer bonded to a finished substrate.

4) During x-ray exposure, a gold-plated mask is used to create the desired pattern in the PMMA wafer. In order to create this mask, a UV mask must first be made. The UV mask blank consists of a plate of $\mathrm{SiO}_{2}$ glass with a thin layer of chromium applied to one side. The desired pattern was etched into the chromium layer, creating the UV mask. The x-ray mask was made using a graphite substrate approximately $150-\mathrm{mm}$ thick. A $30-\mathrm{mm}$ layer of SU-8 (a UV-sensitive photo-resist) was applied to the graphite substrate and cured. It was then placed beneath the UV mask and exposed to an intense UV light source. The exposed graphite mask was then cured further and then placed in a chemical bath that dissolves the unexposed SU-8 and leaves the exposed material. The voids created in the SU-8 layer were filled with a $25-\mu \mathrm{m}$ layer of gold that would act as the mask during x-ray exposure (See Figure 15).

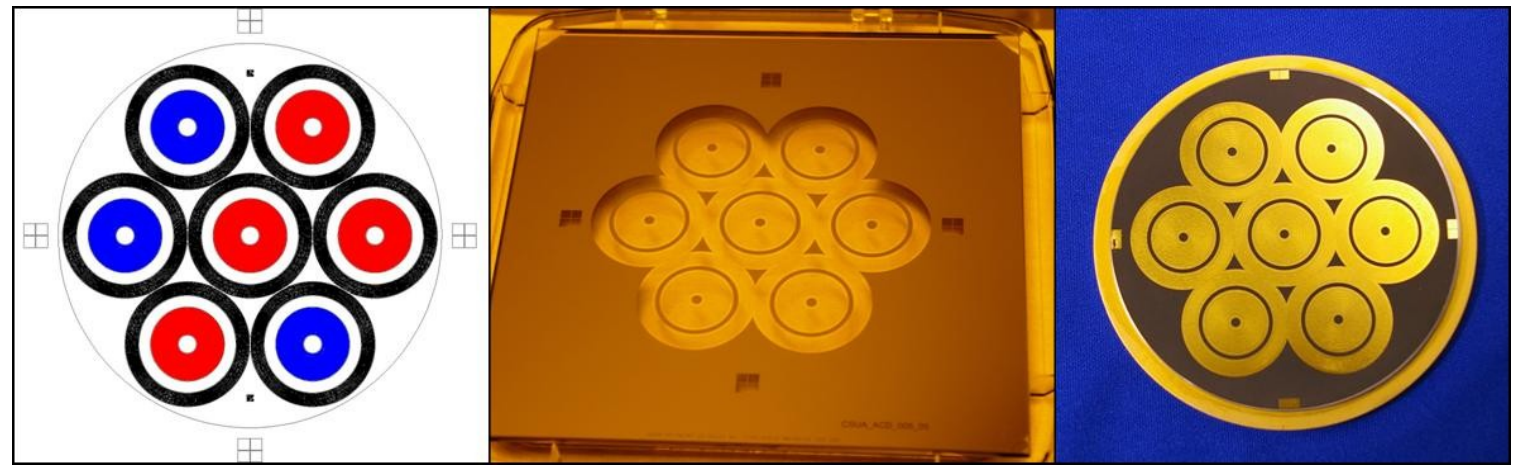

Figure 15. CAD model, UV mask and gold mask (from left to right).

5) The x-ray exposure was conducted on the XLRM2 beamline located at CAMD. This is a "white" spectrum X-ray beamline operating at $1.3 \mathrm{GeV}$ with no optics and 2 beryllium windows. The total exposure dose was approximately $70000 \mathrm{~mA}-\mathrm{min}$. The x-ray energy passed through an x-ray mask that transferred the desired pattern to the PMMA.

6) After x-ray exposure, the glass substrates were returned to Mezzo for development. The substrates were placed in a chemical bath that dissolved away the exposed PMMA. The unexposed PMMA remained in place to create the mold for electroplating. After being thoroughly rinsed, each substrate was secured in a plating fixture and placed in the electroplating bath. The mold remained in the plating bath until nickel deposition filled all of the voids in 
the PMMA wafer. Due to non-uniformity in the deposited nickel layer, the substrates were then sent to CAMD to remove the excess nickel and planarize the surface. The method of planarizing the surface with a "skim pass" on the EDM machine proved disastrous to the glass substrate. During the electroplating process, the stress in the plated nickel was high enough to cause very small cracks to develop in the surface of the glass. A combination of these cracks and the temperature gradient induced by the EDM machine caused the glass substrate to shatter. An improved polishing method using a less aggressive lapping wheel and diamond slurry proved to be successful (see Figure 16).

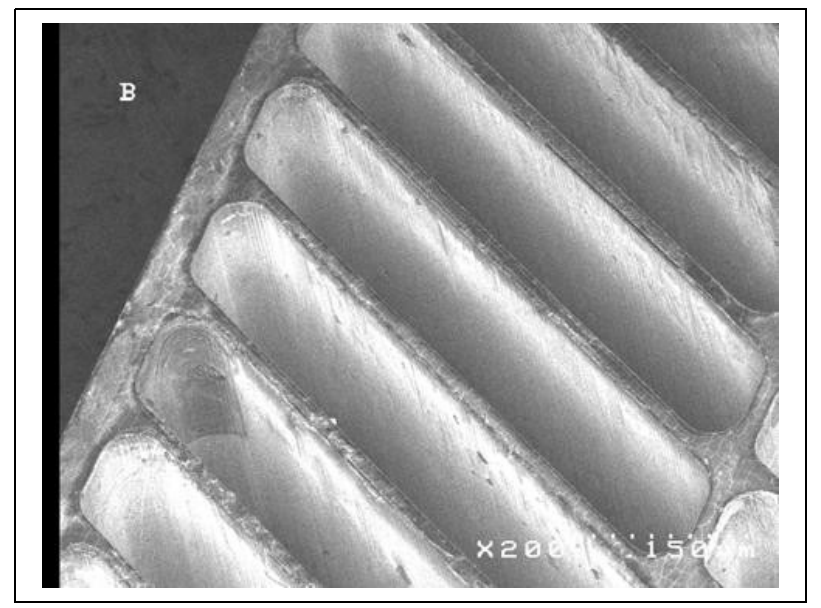

Figure 16. Micrograph of features after polishing.

7) The substrates were then returned to Mezzo Technologies where they were soaked overnight in a strong solvent to remove the remaining PMMA. (See Figure 17a) Once the PMMA was removed, the titanium oxide layer was etched away in a hydrofluoric acid solution. This was the step that released the regenerator disks from the glass substrate (see Figure 17b).

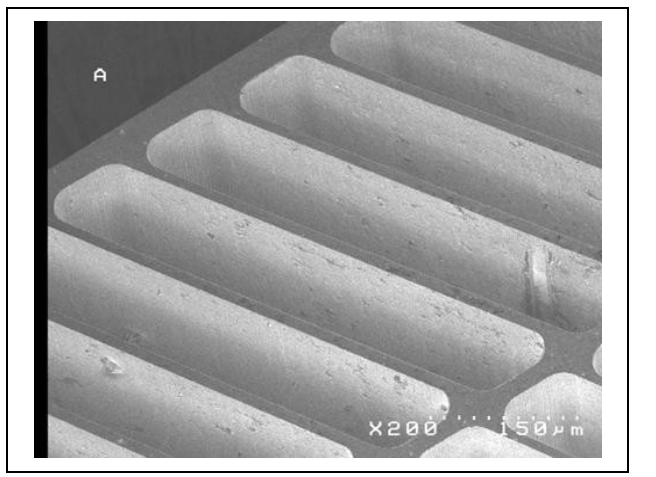

a) Micrograph of features with remaining PMMA removed.

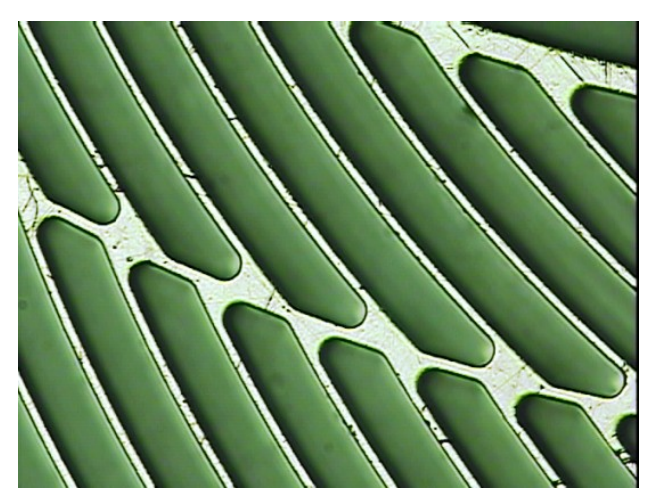

b) Picture of nickel ribs after removal from substrate.

Figure 17. Micrograph of regenerator disks during the final steps of fabrication.

8) Once the required number of nickel regenerator disks had been fabricated, they were brought into the Mezzo clean-room for assembly. Inside the clean-room, the disks were separated into two groups according to their geometry: primary and secondary. Prior to assembly, the disks were bathed in acetone, then bathed in IPA and finally rinsed in running DI water. The disks were then dried in a convection oven and allowed to cool to room temperature. The mandrel and shipping assembly supplied by Sunpower were also cleaned and dried in the same manner. The regenerator disks were stacked on the mandrel by alternating between the primary and secondary types. Once the disks were stacked, the mandrel was placed in the shipping assembly and sealed while inside the clean-room. The sealed assembly was then packaged for delivery via courier service. 


\subsection{Stirling Engine Regenerator Results}

The fabrication process described above was used to fabricate the Stirling engine regenerator for Phase III of this project. Part of a typical part is shown in Figure 17b. The nickel webs are approximately $15 \mu \mathrm{m}$ in width, and arranged in an involute pattern similar to the first regenerator (See Phase II Final Report). The thickness of each disk is approximately $475 \mu \mathrm{m}$.

\section{FTB Test Results and Analysis (Gedeon Associates and Sunpower)}

\section{A. Regenerator Inspection and Installation}

Figure 18 below shows the regenerator in its shipping fixture soon after arrival at Sunpower.

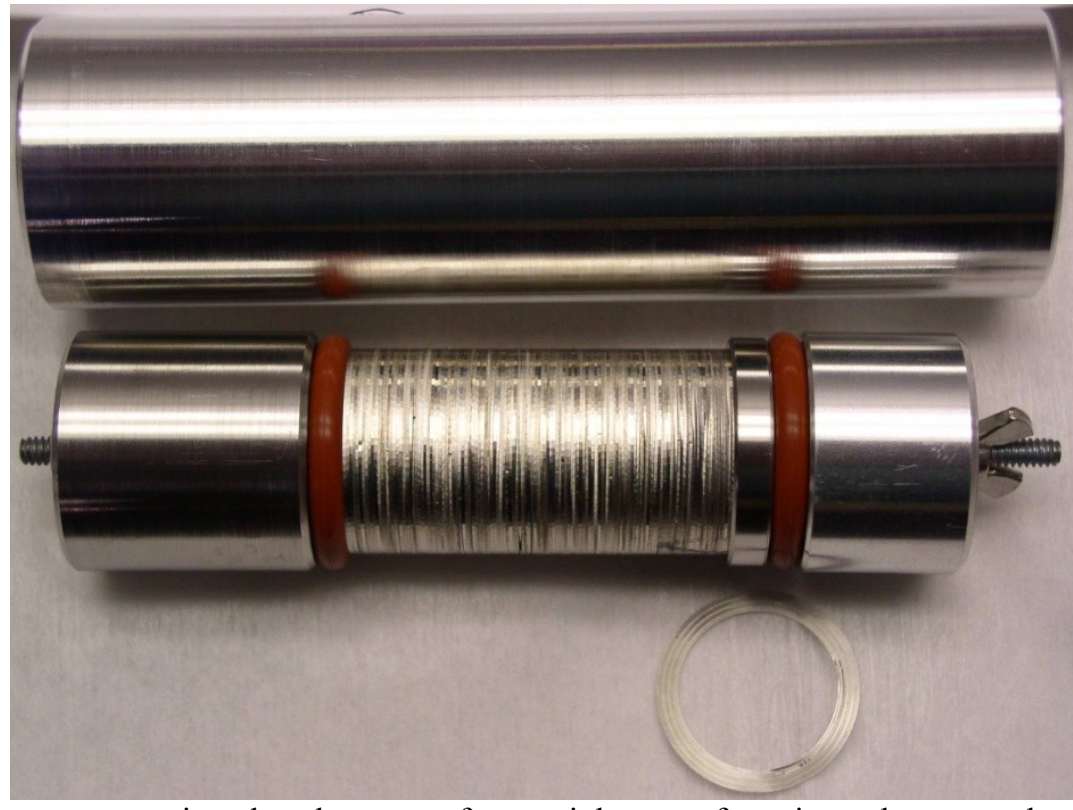

Figure 18. The regenerator in its fixture after arrival at Sunpower.

Some of us were expecting that, because of very tight manufacturing tolerances, the exposed surface of the regenerator stack would look like a smooth cylinder, with the divisions between individual disks barely visible. That is not quite the way it appears, as the close-up view (Figure 19) shows.

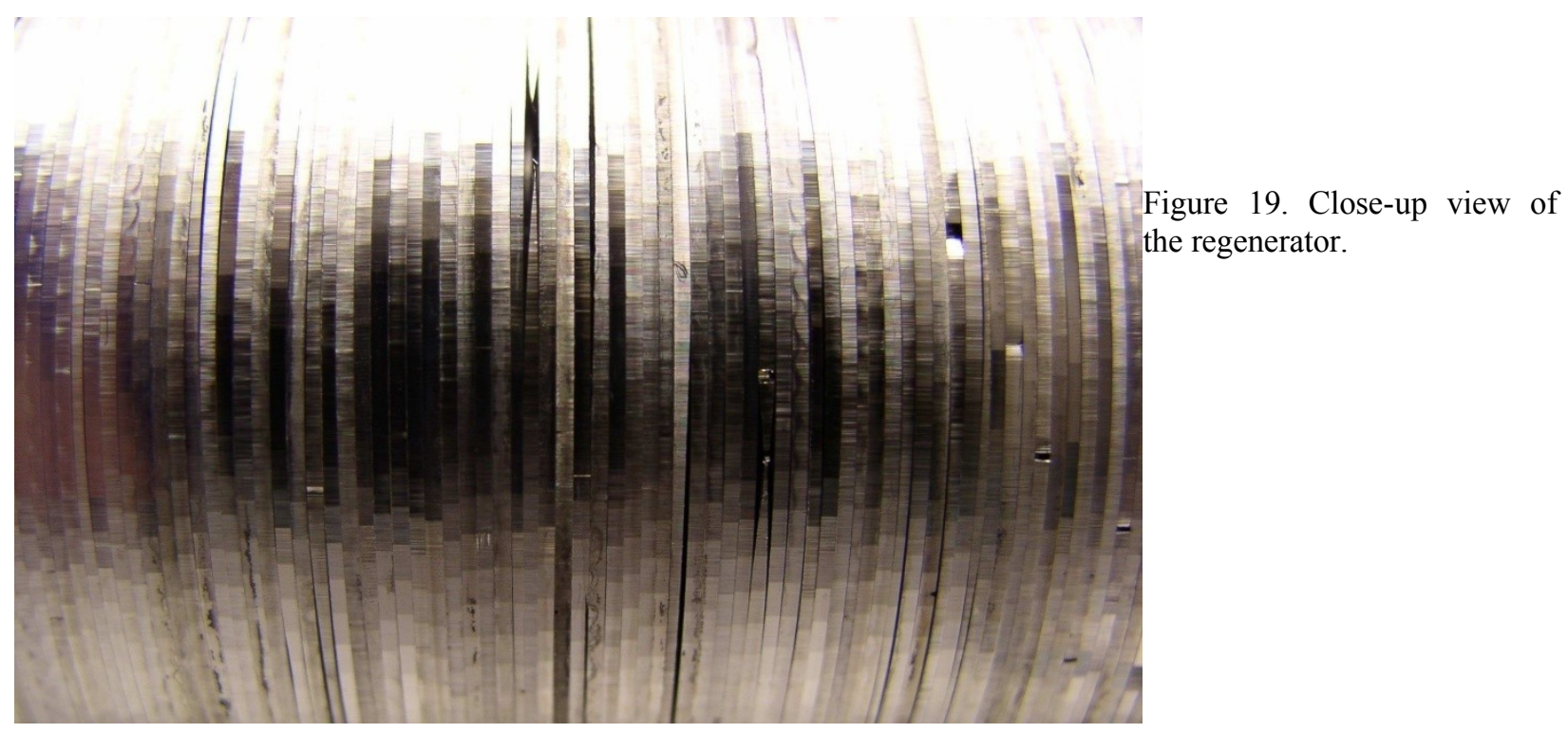

American Institute of Aeronautics and Astronautics 092407 
Some disks are seen to be much thinner than others, and there are thickness variations within individual disks resulting in visible gaps in several places. The local disk thickness even drops to zero in some cases. (See upper center of photo).

\section{Outer Diameter Measurements}

Measurements of the assembled regenerator outer diameter (OD) on the Sunpower optical comparator show that the regenerator is slightly slimmer than the nominal OD by .009 or $.016 \mathrm{~mm}$, depending on who was doing the measurement. Figure 20 below shows the regenerator surface as it appears on Sunpower's optical comparator.

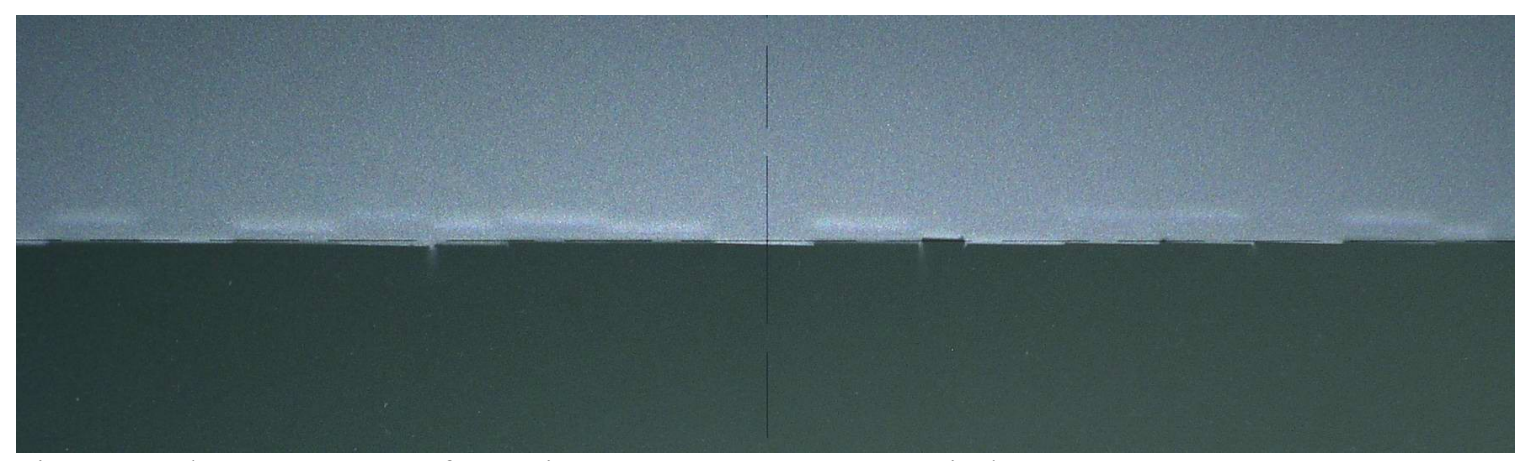

Figure 20. The regenerator surface as it appears on Sunpower's optical comparator.

One end of the regenerator appeared to be slightly bigger than the other.

Based on the measured dimensions, the mean diametric gap between regenerator and heater head could be anywhere from 19 to 51 microns (based on the largest regenerator measurements combined with the smallest head, or vice versa). Assuming concentric location, the worst-case radial gap would be about 25 microns, which is still small compared to the 85 micron involute-foil channel gap.

\section{Overall length}

The regenerator stack length, as measured, varied by $0.14 \mathrm{~mm}$, depending on how tightly the clamping wing-nut at the end of the holding fixture was screwed down. The stack was elastically flexible, probably as a result of the many little gaps produced by disk thickness variations.

\section{Disk Thickness Variation}

We also measured the individual disk thickness by using the optical comparator to measure the distance between steps in the projected profile (See Figure 20 above). Plotted below in Figure 21 are the results of two linear traverses along the regenerator with the regenerator rotated 120 degrees between the two. 
Regen Disk Thicknesses

Measured by DX increments along OD

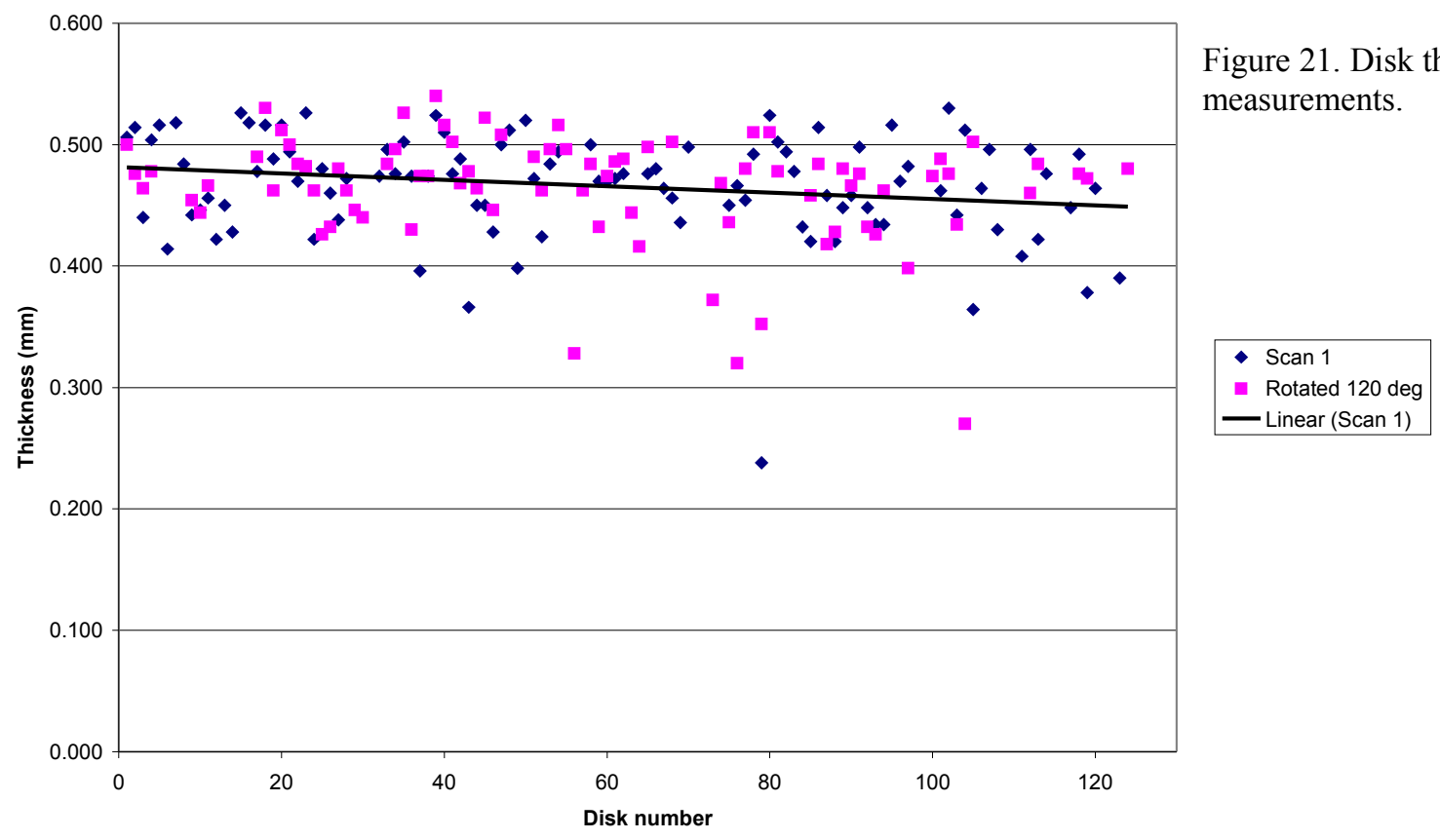

The average disk thickness decreases toward one end of the regenerator at the same time as the disk-to-disk scatter increases. The mean disk thickness is $\mathbf{0 . 4 6 5} \mathrm{mm}$ and the standard deviation is $\mathbf{0 . 0 4 5} \mathrm{mm}$, according to calculations via Excel.

\section{Optical Comparator Methodology}

The optical comparator places the regenerator assembly on a table where its somewhat fuzzy shadow-image is displayed on a screen with cross hairs, as shown in Figure 20. Two dials move the table in X and Y directions and a digital readout displays the table position to an accuracy of 2 microns.

Regenerator diameter measurements required positioning the horizontal cross-hair at a height representative of the local regenerator surface. We ignored several "bumps" where certain disks protruded from the surface by as much as 100 microns. We found that such bumps were localized (disappeared upon rotating the regenerator by 10 degrees, or so) and easily pushed back into place. We are assuming they will continue to be easily pushed into place during final regenerator assembly.

Measuring individual disk thicknesses involved positioning the vertical cross hair at the step transition between successive disks, which was sometimes clear but often a rounded fuzzy bump, difficult to discern, as Figure 20 shows. We scanned most of the regenerator length this way, then rotated the regenerator by about 120 degrees and scanned it again. It was difficult to scan the first few and last few disks because of visual interference from the holding fixture at the two ends of the regenerator.

\section{B.Test Results vs Sage Predictions}

Testing of the microfabricated regenerator in the FTB convertor produced about the same efficiency as testing with the original random-fiber regenerator. But the high thermal conductivity of nickel was responsible for a significant performance degradation with the microfabricated regenerator. Had the microfabricated regenerator been made from a low-conductivity material, the efficiency would have been higher by a factor of 1.04. Had the FTB engine been completely designed to take full advantage of the micro-fabricated regenerator's low flow resistance, the efficiency would likely have been higher still. In any event, there was good agreement between Sage computer modeling and the test data, validating the use of Sage to design and optimize future micro-fabricated regenerators. 


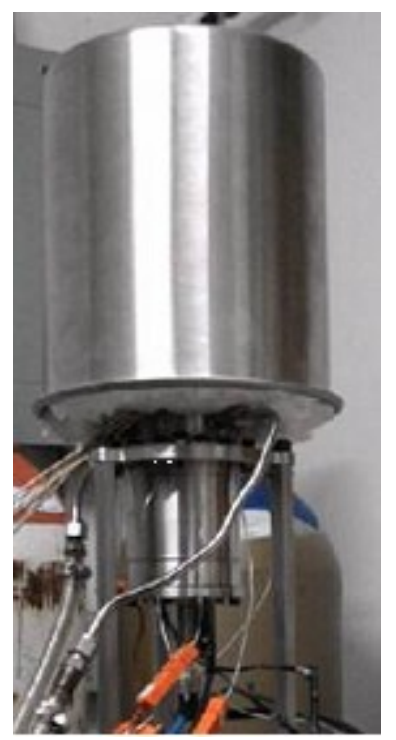

Figure 22. Sunpower Picture of

FTB Engine Test Setup.

Comparing test measurements to Sage model predictions is not as easy as it might seem. The primary test measurements are electrical output power delivered to a load and gross thermal input to the heating elements surrounding the engine head. The primary Sage outputs are PV power delivered to the piston and net thermal input through the engine boundaries. So one is forced to either convert test measurements to Sage outputs or vice-versa. The approach taken in this paper is the first one. Electrical power output is converted to estimated PV power output and gross heat input to net heat input. More about how these things are done later.

First the results. Table 5 compares FTB engine test data against Sage model predictions for the original randomfiber regenerator and the microfabricated regenerator. The random-fiber data points selected for comparison are those with piston and displacer amplitudes and phase close to the microfabricated data points.

Table 5. Comparison Between FTB Engine Test Data and Sage Model Prediction.

\begin{tabular}{|l|c|c|c|c|c|}
\hline \multirow{2}{*}{ Test Data } & \multicolumn{3}{|c|}{ Random-fiber regenerator } & \multicolumn{2}{c|}{$\begin{array}{c}\text { Microfabricated } \\
\text { regenerator }\end{array}$} \\
\hline Date & \multicolumn{3}{|c|}{$7 / 12 / 04$} & $9 / 20 / 04$ & $9 / 20 / 04$ \\
\hline Test point & 4 & 3 & 11 & $1 / 7 / 08$ & $1 / 7 / 08$ \\
\hline Pressure charge (bar) & 32.94 & 36.39 & 36.39 & 2 & 3 \\
\hline Frequency (Hz) & 106.7 & 105.4 & 105.4 & 31.22 & 31.15 \\
\hline T head (C) & 650 & 650 & 649.5 & 104.9 & 103 \\
\hline T rejection (C) & 35 & 30 & 30 & 650 & 649.5 \\
\hline Piston amplitude (mm) & 4.5 & 4.6 & 4.55 & 30.1 & 30.1 \\
\hline Electrical power output (W) & 88.90 & 85.75 & 85.75 & 4.5 & 4.5 \\
\hline Alternator current phase (deg) & 122.00 & 87.1 & 86.6 & 82.6 & 89.1 \\
\hline Alternator electrical efficiency & 0.88 & 0.91 & 0.91 & 125.7 & 103.1 \\
\hline Estimated PV power output (W) & 101.0 & 93.8 & 93.8 & 0.87 & 0.91 \\
\hline Heat input gross (W) & 303.9 & 303 & 303.6 & 95.0 & 98.0 \\
\hline Heat leak insulation (W) & -56.3 & -56.3 & -56.3 & 310.1 & 325.1 \\
\hline Heat input net (W) & 247.6 & 246.7 & 247.3 & -71.7 & -71.7 \\
\hline Electrical efficiency & 0.3590 & 0.3476 & 0.3467 & 238.4 & 253.4 \\
\hline PV efficiency & 0.4078 & 0.3804 & 0.3795 & 0.3465 & 0.3516 \\
\hline
\end{tabular}


Table 5. (Continued) Comparison Between FTB Engine Test Data and Sage Model Prediction.

\begin{tabular}{|l|c|c|c|c|c|}
\hline \multirow{2}{*}{ Sage Comparison } & \multicolumn{3}{|c|}{ Random-fiber regenerator } & \multicolumn{2}{c|}{$\begin{array}{c}\text { Microfabricated } \\
\text { regenerator }\end{array}$} \\
\hline Date & $7 / 12 / 04$ & $9 / 20 / 04$ & $9 / 20 / 04$ & $1 / 7 / 08$ & $1 / 7 / 08$ \\
\hline PV power output (W) & 107.47 & 113.59 & 112.72 & 105.45 & 110.45 \\
\hline Heat input net (W) & 242.3 & 254 & 251.7 & 222.2 & 234.1 \\
\hline PV efficiency & 0.4435 & 0.4472 & 0.4478 & 0.4746 & 0.4718 \\
\hline Sage/Test Ratios & & & & & \\
\hline PV power output ratio & 1.06 & 1.21 & 1.20 & 1.11 & 1.13 \\
\hline Heat input net ratio & 0.98 & 1.03 & 1.02 & 0.93 & 0.92 \\
\hline PV efficiency ratio & 1.09 & 1.18 & 1.18 & 1.19 & 1.22 \\
\hline
\end{tabular}

The numbers in red ("alternator electrical efficiency", "estimated PV power output", "heat input net" and "PV efficiency" are indirectly derived, see Appendix A. Sage consistently over-predicts PV power by about 10-20\% but does much better predicting heat input- within a few percent in all cases once nickel regenerator conduction losses are factored in.

\section{Correcting for Nickel Regenerator Conduction}

During Phase II we had estimated the thermal conduction losses in the nickel part of the microfabricated regenerator as installed in the FTB engine. The estimated loss was a function of disk thickness with the following values calculated:

Table 6. Solid Conduction Losses for 250 \& 500 micron Disk Thicknesses.

\begin{tabular}{|l|l|l|}
\hline Disk thickness (micron) & 250 & 500 \\
\hline Average solid conduction (W) & 3.8 & 11.8 \\
\hline
\end{tabular}

The $3.8 \mathrm{~W}$ loss for the 250 micron disk case was already built into the Sage simulation as a result of the heattransfer correlations used for modeling the microfabricated regenerator being derived from a test sample with that disk thickness. The additional $8.0 \mathrm{~W}$ estimated conduction loss for the 500 micron thick case - the thickness actually used in the FTB regenerator - was not included in the simulation. So one can argue that it is reasonable to add $8.0 \mathrm{~W}$ to the Sage net heat input values, which would bring them significantly closer to the test values. With the $8.0 \mathrm{~W}$ addition, the last part of Table 5 would look like this:

Table 7. Comparison between FTB Engine Test Data and Sage Model Prediction (including 8 W Conduction Losses). The changed values are shown in the table below in bold italic blue font.

\begin{tabular}{|c|c|c|c|c|c|}
\hline \multicolumn{6}{|l|}{ Test Data } \\
\hline Date & $7 / 12 / 04$ & $9 / 20 / 04$ & $9 / 20 / 04$ & $1 / 7 / 08$ & $1 / 7 / 08$ \\
\hline Test point & 4 & 3 & 11 & 2 & 3 \\
\hline Estimated PV power output (W) & 101.0 & 93.8 & 93.8 & 95.0 & 98.0 \\
\hline Heat input gross (W) & 303.9 & 303 & 303.6 & 310.1 & 325.1 \\
\hline Heat leak insulation (W) & -56.3 & -56.3 & -56.3 & -71.7 & -71.7 \\
\hline Heat input net (W) & 247.6 & 246.7 & 247.3 & 238.4 & 253.4 \\
\hline Electrical efficiency & 0.3590 & 0.3476 & 0.3467 & 0.3465 & 0.3516 \\
\hline PV efficiency & 0.4078 & 0.3804 & 0.3795 & 0.3984 & 0.3867 \\
\hline \multicolumn{6}{|l|}{ Sage Comparison } \\
\hline PV power output (W) & 107.47 & 113.59 & 112.72 & 105.45 & 110.45 \\
\hline Heat input net (W) & 242.3 & 254 & 251.7 & 230.2 & 242.1 \\
\hline PV efficiency & 0.4435 & 0.4472 & 0.4478 & 0.4581 & 0.4562 \\
\hline \multicolumn{6}{|l|}{ Sage/Test Ratios } \\
\hline PV power output ratio & 1.06 & 1.21 & 1.20 & 1.11 & 1.13 \\
\hline Heat input net ratio & 0.98 & 1.03 & 1.02 & 0.97 & 0.96 \\
\hline PV efficiency ratio & 1.09 & 1.18 & 1.18 & 1.15 & 1.18 \\
\hline
\end{tabular}

As a result, Sage comes within about $3-4 \%$ of the net heat input calculated for the actual tests, suggesting that the added nickel thermal conduction is real. 
Alternately, one can ask what the tested efficiency might have been had the microfabricated regenerator been made of a low-conductivity material. In that case, the evidence suggests that the test heat input would have been about $12 \mathrm{~W}$ lower and the electrical efficiency higher by a factor of about 1.04 . So the tested electrical efficiency for data point 3 on 1/7/2008 (see Table 7) might have been $36.53 \%$, instead of $35.16 \%$.

\section{Regenerator Flow Friction and Enthalpy Loss Trades}

We have understood all along that the FTB engine was not optimal for demonstrating the microfabricated regenerator. It did not permit taking full advantage of the low flow resistance offered by the involute foil structure. The FTB engine requires a certain amount of pressure-drop power dissipation across the heat-exchanger plus regenerator flow path in order to balance the power produced by the displacer drive rod. We decided not to modify that rod for the microfabricated regenerator redesign. As a result, the microfabricated regenerator pressure drop is higher than it might have been, and there are also higher pressure drops in other components.

Table 8 compares the main losses for the two FTB regenerators, as simulated by Sage. Flow-resistance losses are tabulated as available-energy losses, which are the actual pumping losses multiplied by the appropriate temperature ratio, $T_{a m b i e n} / T_{h x}$ (ambient / heat exchanger temperature), in effect assuming that some of the pumping loss suffered at high temperatures is recoverable. Enthalpy flow losses are actual thermal energy flows that add directly to net heat input.

The red "Wdis" entries (shown in Table 8) are the simulated powers delivered to the displacer at its observed amplitude and phase angle after all flow-friction dissipations have been accounted for. In the case of the random fiber regenerator, there is an extra $1.95 \mathrm{~W}$ drive power left over, suggesting additional flow resistance in the actual engine - probably in the regenerator. In the case of the microfabricated regenerator, there seems to be slightly less overall flow dissipation than modeled.

So according to the way Sage saw things during the design process, it had to maintain about $5.9 \mathrm{~W}$ of pumpingdissipation losses in the microfabricated regenerator design, which it did by distributing the losses as indicated in Table 8. It managed to do this while at the same time reducing enthalpy flow losses by about $6 \mathrm{~W}(40 \%)$ compared to the random-fiber enthalpy loss. Sage would have done better if it had not had to maintain the $5.9 \mathrm{~W}$ pumping dissipation losses, although by exactly how much is not clear. But every watt saved in pumping dissipation is another watt added to PV power output.

The $6 \mathrm{~W}$ reduction of regenerator enthalpy loss in Table 8 suggests that the microfabricated regenerator should have produced slightly higher engine efficiency than the random-fiber regenerator. But, because of the increased nickel regenerator conduction, this was not the case. Engine efficiency was about the same. If future Sage models correctly account for regenerator solid conduction, then it appears that Sage will come very close to predicting the performance of a microfabricated regenerator.

Table 8. Sage Model Prediction, Enthalpy Losses referenced to FTB Engine Test Data.

\begin{tabular}{|l|c|c|}
\hline & Random-fiber & Microfab \\
\hline $\begin{array}{l}\text { Test } \\
\text { Reference }\end{array}$ & & \\
\hline Date & $7 / 2 / 2004$ & $1 / 7 / 2008$ \\
\hline Test point & 2 & 3 \\
\hline $\begin{array}{l}\text { Sage AEfric, available energy- } \\
\text { friction, losses (W) }\end{array}$ \\
\hline Rejector & 0.32 & 0.41 \\
\hline Jet diffuser C & NA & 0.61 \\
\hline Regenerator & 3.34 & 4.7 \\
\hline Jet diffuser H & NA & 0.34 \\
\hline Acceptor & 0.16 & 0.14 \\
\hline Wdis & 1.95 & -0.35 \\
\hline Total & $\mathbf{5 . 8}$ & $\mathbf{5 . 9}$ \\
\hline \multicolumn{2}{|c|}{} & $\mathbf{1 6 . 5}$ \\
\hline Sage Enthalpy Flow (W) & \\
\hline Regenerator & & \\
\hline
\end{tabular}




\section{Estimated Alternator Efficiency}

In Table 5 above, the alternator efficiency is not measured directly but rather estimated from a simple alternator loss model calibrated to the data. The estimated PV power output is then the measured electrical output divided by the estimated alternator efficiency. Appendix A shows more details in estimating the alternator efficiency.

\section{Net Heat Input}

The net heat input in Tables $5 \& 7$ is derived from the total electrical input to the heater elements, less insulation heat loss estimated from separate testing and data analysis. The insulation heat loss is a relatively large number. It was $56.3 \mathrm{~W}$ or about $19 \%$ of the gross heat input for the random-fiber regenerator tests and $71.7 \mathrm{~W}$ or about $23 \%$ of the gross heat input for the microfabricated regenerator tests. The two are different because the method of heating the head was different for the two cases. For the random-fiber tests, there were heating elements directly attached to the head - on the end dome and acceptor walls. For the microfabricated tests, the heating elements were attached to a nickel block bolted to the head.

In both cases, the insulation loss is measured with the test setup brought to operating temperature with the engine not running. The total electrical heat input is measured and the thermal losses down the engine structures calculated. The difference is attributed to insulation loss. The principle sources of error are the calculated losses down the various engine and structural components.

In the case of the random-fiber tests, the engine structure during heat-leak testing includes the pressure wall, regenerator, displacer cylinder, displacer, and heater support structure.

In the case of the microfabricated tests, the heat-leak testing was done two ways. First, the test was run, as described above, with the full engine in place. Second, a test was done with a "dummy" engine, consisting of only a pressure wall stuffed with fibrous ceramic insulation. The second method of testing is more accurate because there are fewer components, besides the heater insulation itself, down which heat is flowing. It is the basis for the $71.7 \mathrm{~W}$ reported in the table.

The $71.7 \mathrm{~W}$ insulation loss for the microfabricated regenerator tests is probably more accurate than the $56.3 \mathrm{~W}$ for the random-fiber regenerator tests, although the error bands are unknown.

\section{Summary}

Currently, Stirling convertor regenerators are usually made of woven screens or random fibers. These types of structures suffer from the following features: 1) locally non-uniform flows, 2) local variations in porosity which would result in local mismatches in flow channels that would contribute to axial thermal transport, 3) high flow friction combined with considerable thermal dispersion, a thermal loss mechanism that causes an increase in apparent axial thermal conduction, 4) wire screens require long assembly times which tends to increase their cost, and 5) for space engines, there must be assurance that no fibers of the matrix will eventually work loose and damage vital convertor parts during the mission.

Research efforts thus far have shown that attractive features for effecting high fluid-to-matrix heat transfer with low pressure drop are a matrix in which: a) the heat transfer surface is smooth, b) the flow acceleration rates are controlled, c) flow separation is minimized and d) passages are provided to allow radial mass flow for a more uniform distribution when the inlet flow or the in-channel characteristics are not radially uniform. It is thought that properly designed microfabricated regular geometries could not only reduce pressure drop, maintain high heat transfer and allow some flow redistribution when needed, but could show improved regenerator durability for long missions. The goal of the current NASA project is to develop a new regenerator of high durability and high efficiency, using emerging microfabrication technology. In addition to the benefit to Stirling convertor space-power technology, such regenerator development will also benefit Stirling cycle coolers and NASA's many cryocoolerenabled missions. This project was conducted in three phases, I, II and III. Phase I \& II were conducted by CSU (lead institution), University of Minnesota (UMN), Sunpower, Gedeon Associates, Infinia and Mezzo, while Phase III was conducted by CSU, Sunpower, Gedeon Associates and Mezzo.

In Phase I of this project, a microscale regenerator design was developed based on state-of-the-art analytic and computational tools. For this design, a 6-9\% engine-efficiency improvement was projected. A manufacturing process was identified and a vendor (International Mezzo Technologies) was selected to apply it. Mezzo completed EDM tools for fabricating layers of the chosen involute-foil microregenerator design, based on the team's specifications. Also, a Large-Scale-Mock-Up (LSMU) involute-foil regenerator was designed and fabrication had begun at UMN. Computational Fluid Dynamics (CFD) analysis for different geometries was employed to model the fluid flow and heat transfer under both steady and oscillatory-flow conditions. The effects of surface roughness were 
included. Several geometries, including lenticular, parallel plates (equally/non-equally spaced), staggered parallel plates (equally/non-equally spaced) and 3-D involute-foils, were studied via CFD. The modeling was applied to both the microscale involute-foil regenerator and to the LSMU model of it.

The Phase II final report of this project covered in detail the preliminary design process that was used for adapting a microfabricated regenerator to a Sunpower FTB (Frequency Test Bed) Stirling convertor. The FTB convertors produce about $80-90 \mathrm{~W}$ of electrical power with a heat input of $220 \mathrm{~W}$ and are the direct ancestors of the advanced Stirling convertors now under development by Sunpower and GRC for future NASA space missions. They were originally designed for random-fiber regenerators. During Phase II, several tasks were completed: The team a) developed a preliminary microfabricated regenerator design based on its similarity to a parallel-plate structure, $b$ ) analyzed radiation losses down the void part of the regenerator, c) analyzed thermal conduction losses in the solid part of the regenerator, using closed form as well as two-dimensional computational analysis, d) built a prototype microfabricated regenerator for use in the NASA/Sunpower oscillatory flow test rig, e) tested that regenerator and derived design correlations for heat transfer and pressure drop, and f) performed system modeling of a FTB convertor with a microfabricated regenerator using the Sage simulation software - first using theoretical parallelplate correlations for heat transfer and pressure drop, then with the correlations derived from actual test data.

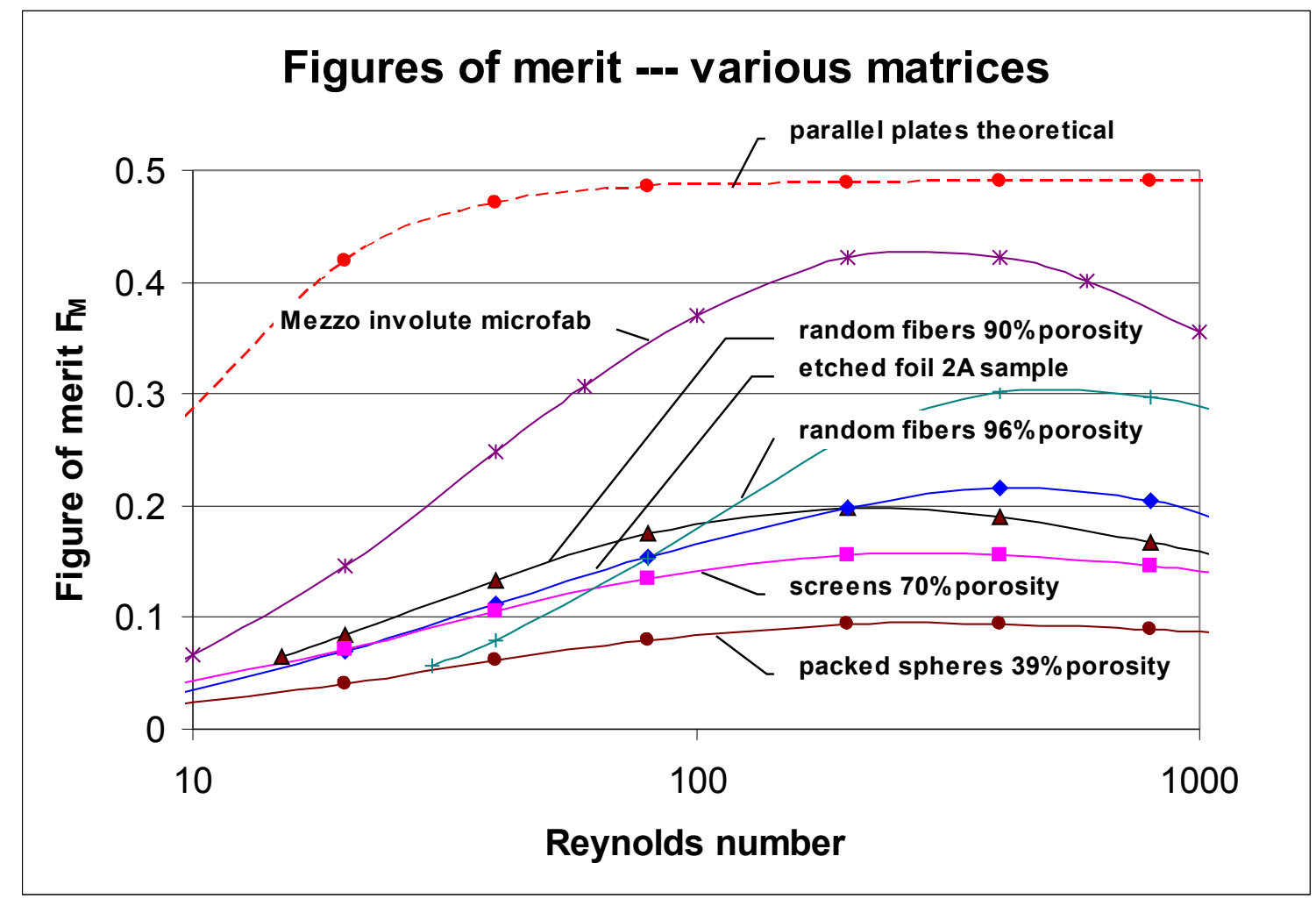

Figure 23. Figures of merit for various matrices.

Results of testing different type of regenerator matrices in the NASA/Sunpower oscillating flow test rig are summarized in Figure 23. The microfabricated regenerator has a figure of merit substantially higher than the other regenerator types, including the $90 \%$ random fiber regenerator. Figure of merit is defined as follows: 


$$
F_{M}=\frac{1}{f\left(\frac{R_{e} P_{r}}{4 N_{u}}+\frac{N_{k}}{R_{e} P_{r}}\right)}
$$

$\begin{array}{cl}R_{e} & \text { Reynolds number } \\ P_{r} & \text { Prandtl number } \\ f & \text { Friction factor } \\ N_{u} & \text { Nusselt number } \\ N_{k} & \text { Thermal dispersion conduction } \\ & \text { enhancement }\end{array}$

These results show that the segmented-involute-foil has a figure-of-merit about twice that of the $\sim 90 \%$ porosity random-fiber material currently used in the small 50-100 W Stirling engines recently manufactured for NASA.

During Phase III, the subject of this paper, the team finalized the regenerator design, fabricated and installed it in a FTB Stirling convertor, tested it, and analyzed the test results.

The geometrical features of the segmented-involute-foil regenerator include: 1) mean disk thickness $=0.465$ $\mathrm{mm}$, 2) channel gap $=0.086 \mathrm{~mm}, 3)$ web wall thickness $=0.014 \mathrm{~mm}$ and 4) inner and outer wall thickness $=0.03$ $\mathrm{mm}$. These features resulted in a hydraulic diameter, $D_{\mathrm{h}}=0.159 \mathrm{~mm}$, and porosity, $\beta=0.837$. Random-fiber flow diffusers were located at either end of the regenerator for purposes of spreading the incoming flow jets from the narrow channels of the acceptor or rejector heat exchangers. The diffuser design was backed by 2-D computational modeling. The random fiber material was compressed to $0.6 \mathrm{~mm}$ thickness, and this resulted in a porosity of $\beta=$ 0.88 . The length of the space occupied by the regenerator is defined by the outer pressure wall of the heater head. A calculation shows that the relative thermal expansion between the nickel regenerator and stainless-steel pressure wall is only about $0.030 \mathrm{~mm}$ in heating from room temperature to operating temperature, with the pressure wall expanding more.

The CFD model that was used to simulate the above case (diffuser/acceptor interface) is a 2-D geometry with parallel plates under steady state conditions. The Fluent commercial code was utilized in the simulation. Version 6.3.26 was used with 213,560 cells, and the code ran on a Dell Precision PWS670, Intel (R) Xeon (TM) with a 2.8 $\mathrm{GHz}$ CPU. A V2f turbulence model was utilized in the simulation. The CFD results indicate an optimum configuration has a gap of 133 micron at the jet exit. Then the rest of the $0.6 \mathrm{~mm}$ space, between the gap and the parallel plates simulating the involute foil, is filled with random fiber.

International Mezzo Technologies manufactured the above specified design. LIGA was chosen as the preferred micromachining method to fabricate high-aspect-ratio microfeatures (features with extreme height/width ratios) with nearly vertical, smooth sidewalls. The Center for Advanced Microstructures and Devices (CAMD) in Baton Rouge, LA has a synchrotron storage ring that emits a synchrotron radiation spectrum ideal for x-ray lithography, or micromachining. This facility was used for the x-ray exposures of this project. Once the required number of nickel regenerator disks had been fabricated, they were brought into the Mezzo clean-room for assembly. Inside the cleanroom, the disks were separated into two groups according to their geometry: primary and secondary. Prior to assembly, the disks were bathed in acetone, then bathed in isopropyl alcohol and finally rinsed in running de-ionized water. The disks were then dried in a convection oven and allowed to cool to room temperature. The mandrel and shipping assembly supplied by Sunpower were also cleaned and dried in the same manner. The regenerator disks were stacked on the mandrel by alternating between primary and secondary types. Once the disks were stacked, the mandrel was placed in the shipping assembly and sealed while inside the clean-room. The sealed assembly was then packaged for delivery via courier service.

Upon arrival of the segmented-involute-foil regenerator at Sunpower, it was evaluated for its overall structure and specific dimensions, including outer diameter via the Sunpower optical comparator, overall length and disk thickness variation. All dimensions met specifications within allowed tolerances. 


\section{Conclusions and Recommendations}

The microfabricated regenerator was assembled into the Sunpower Frequency-Test-Bed (FTB) convertor, and the convertor was tested. The test results showed a PV power output of $98 \mathrm{~W}$ and an electrical efficiency of $35.16 \%$. The Sage model results came within 3-4\% of the test data for the net heat input (see Table 7).

Testing in the FTB convertor produced about the same efficiency as testing with the original random-fiber regenerator. But the high thermal conductivity of nickel, the material used for the microfabricated regenerator, was responsible for a significant performance degradation. Had the microfabricated regenerator been made from a lowconductivity material, the efficiency would have been higher by a factor of 1.04. Had the FTB engine been completely redesigned to take full advantage of the microfabricated regenerator's low flow resistance, the efficiency would likely have been higher still. In any event, there was good agreement between Sage computer modeling and the test data, validating the use of Sage to design and optimize future microfabricated regenerators.

Beyond this Phase III effort, the microfabrication process needs to be further developed to permit microfabrication of higher temperature materials than nickel. NASA and Sunpower are currently developing an 850 ${ }^{\circ} \mathrm{C}$ engine for space-power applications. And a potential power/cooling system for Venus applications could need regenerator materials capable of temperatures as high as $1200{ }^{\circ} \mathrm{C}$. Early Mezzo attempts to EDM stainless steel, using a LiGA-developed EDM tool, involved a burn time (dependent on EDM machine setting) that was much too large to be practical. Some possible options for further development of a microfabrication process for hightemperature involute-foils are:

(1) Optimization of an EDM process for high temperature materials that cannot be processed by LiGA only. Burn times can be greatly reduced by higher-power, EDM-machine settings than originally used, in Phase I, by Mezzo, but "overburn," i.e. the gaps between the EDM tool and the resulting involute-foil channels, increases with higher powers".

(2) Development of a LiGA-only process for some high-temperature alloy, or pure metal that would be appropriate for the regenerator application. Pure platinum would work but has very high conductivity, which would tend to cause larger axial regenerator losses, and is very expensive.

(3) Microfabrication of an appropriate ceramic material for high-temperature regenerators. Structural properties of ceramics, which tend to be brittle, would be a concern. Matching of ceramic-regenerator and metalregenerator-container coefficients-of-thermal-expansion would also likely be a problem area.

\section{Appendix A: Estimated Alternator Efficiency (Gedeon Associates)}

In Tables $5 \& 7$, the alternator efficiency is not measured directly but rather estimated from a simple alternator loss model calibrated to the data. The estimated PV power output is then the measured electrical output divided by the estimated alternator efficiency.

The reason for this approach is that the engine PV power measurements are not very accurate and not available at all for the microfabricated regenerator tests. For the random-fiber regenerator tests, the piston PV power output was measured, but the electrical power measurements are more accurate since they are based on true integrated electrical power calculations performed by a dedicated electrical power meter (Yokogawa) designed for that task. PV power on the other hand is calculated in terms of pressure and piston amplitudes and their relative phase angle. It is affected by transducer errors and is a "phasor-math" calculation rather than an actual time integration. Neither piston position nor pressure are recorded by a fast-sampling data acquisition system.

For purpose of this memo, the PV power calculations are only used to calibrate a formula for alternator efficiency as a function of current phase angle, which is available for all the tests. Actually only one PV power calculation is used for that purpose, the one for the 7/12/04 data point. That point was chosen because alternator efficiency was lowest for that point, thereby producing the biggest difference between PV and electrical power and arguably the most accurate measurement of alternator efficiency.

The simple alternator-loss model amounts to the observation that the alternator electrical loss, $W_{\text {loss }}$, scales as the square of the length of the alternator force phasor imposed on the piston - the length of arrow $\boldsymbol{F}$ in the sketch below. This follows because the alternator force is proportional to electrical current, and the electrical losses grow as current squared $\left(W_{\text {loss }} \propto I^{2} R\right.$ ). The useful electrical output, $W_{e}$, on the other hand is proportional to the square of the length of force component, $\boldsymbol{F}_{\boldsymbol{d}}$, in phase with piston velocity, because that is the component absorbing power from the piston. For a given power output, the electrical loss is smallest when the current phase angle, $\theta$, (relative to the piston motion) is 90 degrees. When the current phase differs from 90 degrees, the alternator force is also helping 
to resonate the piston by providing a force component, $\boldsymbol{F}_{\boldsymbol{s}}$, in phase with the piston spring. The sketch below illustrates the resultant alternator force phasor, $\boldsymbol{F}$, and its drive and spring components, $\boldsymbol{F}_{\boldsymbol{d}}$ and $\boldsymbol{F}_{\boldsymbol{s}}$, for the case when current phase, $\theta$, is greater than 90 degrees.

\section{Alternator Force Phasor Diagram}

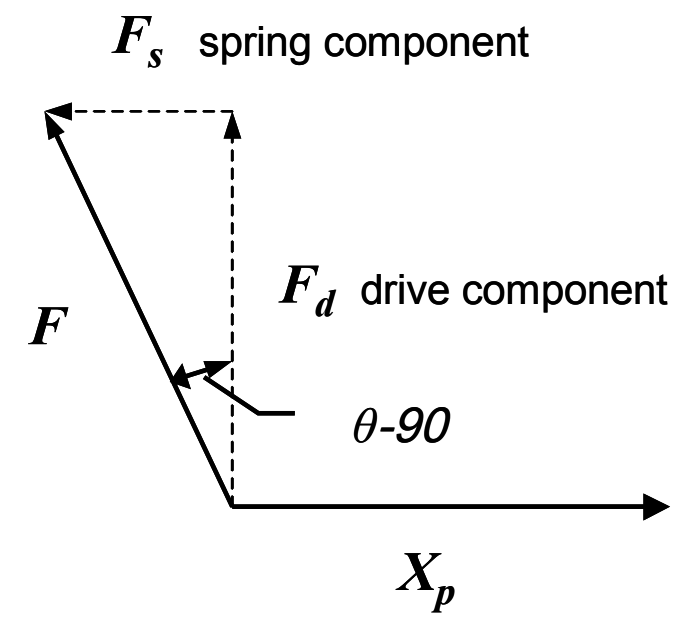

Applying some trigonometry to this model the ratio $W_{\text {loss }} / W_{e}$ is proportional to $1 / \cos ^{2}(\theta-90)$. Introducing a calibration parameter $c$, it follows that alternator electrical efficiency, $\eta_{e}$, may be written

$$
1-\eta_{e}=\frac{W_{\text {loss }}}{W_{e}}=\frac{c}{\cos ^{2}(\theta-90)}
$$

According to the measured efficiency of the 7/12/2004 data point (electrical output / calculated PV power), calibration parameter $c$ has the value 0.086 . This formula, applied to the other measured current phase angles, gives the alternator electrical efficiency values in the table.

\section{Acknowledgments}

The work described in this paper was performed for the NASA Science Mission Directorate (SMD) and the Radioisotope Power System (RPS) Program.

\section{References}

${ }^{1}$ Tew, R.C., Ibrahim, M.B., Danila, D., Simon, T., Mantell, S., Sun, L., Gedeon, D., Kelly, K., Malean, J., Wood, J.G., Qiu, S., (2007), “A Microfabricated Involute-Foil Regenerator for Stirling Engines," NASA/TM-2007-214973 ${ }^{2}$ Ibrahim, M.B., Danila, D., Simon, T., Mantell, S., Sun, L., Gedeon, D., Qiu, S., Wood, J.G., Kelly, K., and McLean, J., (2007), "A Microfabricated Segmented-Involute-Foil Regenerator for Enhancing Reliability and Performance of Stirling Engines: Phase II Final Report for the Radioisotope Power Conversión Technology NRA Contract NAS3-03124," NASA Contractor Report, NASA/CR-2007-215006.

${ }^{3}$ Organ, A.J., (2000), "Two Centuries of Thermal Regenerator," Proceeding of the Institute of Mechanical Engineering, Part C, Journal of Mechanical Engineering Science, 214(NoC1):pp. 269-288.

${ }^{4}$ Ibrahim, M.B., Veluri, S., Simon, T., Gedeon, D. "CFD Modeling of Surface Roughness in Laminar Flow"

Paper\#AIAA-2004-5585, 2nd International Energy Conversion Engineering Conference, 16-19, August 2004, 
Providence, R.I.

${ }^{5}$ Ruhlich, I. and Quack, H. (1999) “Investigations on Regenerative Heat Exchangers," Cryocoolers 10, edited by R.G. Ross, Jr., Klewer Academic/Plenum Publishers, p. 265-274.

${ }^{6}$ Wood, J.G., Carroll, C. and Penswick, L.B., "Advanced 80 W Stirling Convertor Development Progress", 2005 STAIF paper.

${ }^{7}$ Gedeon, D., Sage Stirling-Cycle Model-Class Reference Guide, 3rd edition, Gedeon Associates, Athens, Ohio, 1999.

${ }^{8}$ FLUENT, Inc., 2005. Fluent 6.3 - User Guide. 